Research Article

\title{
Design Criterion and a Technical Approach for the Controlled Seismic Behavior of Continuous Girder Bridges
}

\author{
Hao Gao, ${ }^{1}$ Yanchen Song, ${ }^{1}$ Junjie Wang ${ }^{D},{ }^{1}$ and Huijie Liu ${ }^{1,2}$ \\ ${ }^{1}$ College of Civil Engineering, Tongji University, Shanghai 200092, China \\ ${ }^{2}$ China State Construction International Holdings Limited, Shenzhen 518057, China
}

Correspondence should be addressed to Junjie Wang; jjwang@tongji.edu.cn

Received 18 June 2019; Revised 26 August 2019; Accepted 5 September 2019; Published 30 October 2019

Academic Editor: Miguel Neves

Copyright $(2019$ Hao Gao et al. This is an open access article distributed under the Creative Commons Attribution License, which permits unrestricted use, distribution, and reproduction in any medium, provided the original work is properly cited.

Seismic design involving "fuse components" between the superstructure and substructure can improve the seismic performance of continuous girder bridges during strong earthquakes by ensuring an elastic working state. The mechanical properties of the "fuse components" directly affect the seismic behavior of continuous girder bridges, and many theoretical and experimental studies of isolation devices to achieve the controlled seismic behavior of continuous girder bridges have been carried out, and some devices are in use in large-scale construction projects. However, there is a lack of evidence from structures that have been subject to earthquakes. Test results show that the shear behavior of isolation bearings is unpredictable and the friction behavior is uncontrollable. Further, limiting devices often suffer from an insufficient deformation capacity and have large space requirements. Therefore, we propose a new type of spherical steel bearing and two kinds of large-stroke steel damping devices with different space requirements. The full-scale test results reveal that the bearing has strong controllability with respect to shearing, stable friction behavior after fracture, and little unpredictability in the friction-based processes. Furthermore, the large-stroke steel damping device shows a full hysteresis curve and excellent energy dissipation characteristics. Finally, using a continuous girder bridge as an example and combined with the results of mechanical tests, the effectiveness of the controlled design criterion was verified using numerical simulations. The calculated results show that, compared with conventional fixed bearings, the shear and bending moments are decreased by $60 \%$ and $53 \%$, respectively, and the ratio of both the shear and bending moment response of the pier bottom to its capacity is less than 0.5 . However, the ratio of the maximum deformation of the damper to its capacity is only 0.28 , and the residual displacement is $0.01 \mathrm{~m}$. Therefore, an alternative scheme is provided for postearthquake maintenance and replacement.

\section{Introduction}

Small- and medium-span girder bridges are an important component of the highway traffic network in China. As knowledge concerning earthquake damage to bridges has accumulated, the concept of seismic bridge design has developed. After the Wenchuan earthquake, it was found that most of the girder bridges with plate rubber bearings did not achieve the design goal of having ductile seismic resistance [1]. Through investigation, it was found that the girder body was directly placed on the plate rubber bearing, and there was no connection between the girder body and the bearing or there was no connection between the bearing and the pier platform. Consequently, during the earthquake, slip occurred because of the plate rubber bearing. These unexpected "slippage" behaviors reduced the degree of damage to the pier and foundation, but the residual displacement of the corresponding girder body was generally larger. Thus, the problem of how to limit the girder displacement effectively without obviously increasing the seismic force of the pier has become crucial in the seismic design of this kind of bridge. Xiang et al. [2-5] studied the slippage mechanism of plate rubber bearings through experiments and discussed the seismic response characteristics of plate rubber bearings with different types of transverse limit devices. In addition, the seismic performance of an X-shaped steel damper was tested using shaking table tests. The tests revealed that the plate rubber bearing, together with the limiting device, is 
damaged or even sacrificed, and the inertial force of the girder transferred to the substructure reaches a maximum value, resulting in some damage isolation [6]. Such design ideas are reflected in various seismic design specifications; for example, when the Ministry of Transportation of the State of Illinois revised Part 14 of the American Association of State Highway and Transportation Official's (AASHTO) Load and Resistance Factor Design Bridge Design Specification (LRFD Code), it suggested that the bearings could be used as "sacrificial units" under extreme loads $[7,8]$. The bearings are clearly regarded as "fuses" in large earthquakes in the California Department of Transportation (Caltrans) earthquake specification [9], and the necessity and importance of effective displacement constraint mechanisms and energy consumption mechanisms are also emphasized in this code. Generally, a more reasonable reaction force for the plate rubber bearing is less than $2 \mathrm{MN}$, whereas a continuous girder bridge with large span not only requires the support to adapt to the larger deformation (displacement and rotation angle) of the girder but also requires a higher vertical bearing capacity. Therefore, steel supports are more economical and reasonable [10]. To transfer the isolation concept using slide plate rubber bearings to continuous girder bridge design, it is particularly important to identify how to use steel bearings as "sacrificial elements."

Unlike plate rubber bearings, the fuse configuration is the main technical approach to realize an isolation protection mechanism with steel supports. Under the normal service conditions of a bridge structure, sufficient stiffness and strength are provided, and shear occurs under earthquake action, thus realizing the transformation from a conventional system to an isolated system. Filipov et al. [11-13] conducted full-scale quasistatic tests for the weak anchors and weak pintles of a low-profile fixed support. The test results showed that the installation precision in the weak pintles at the connection of the top and bottom steel bearing plates has a large influence on the failure mode, but the capacity and mechanistic transition to the fused state was less reliably predicted for the weak pintles. However, the use of weak anchors at the connection of the bottom plate to the concrete allowed reasonable prediction of the fuse capacity. The test curve of the whole process for the two cases is shown in Figure 1. Peng and Guo [14, 15] carried out pintle shear tests, and linear and nonlinear calculation models were obtained. Combined with double spherical seismic isolation bearing, shaking table tests were conducted, and the shear effect of the pintles and the accuracy of different calculation models were investigated.

In terms of the displacement restraint mechanism, in addition to the X-shaped steel damper recommended by Xiang et al., a triangular steel damper was examined by Zhou et al. [16] using Sutong Bridge as the engineering case study. Zhou and coworkers conducted shaking table tests at a scale ratio of $1 / 35$ and verified the mechanism of energy dissipation and limiting displacement of the triangular steel damper used as a transverse damping device in this cablestayed bridge. Generally, the lateral drift rate of the triangular damper can reach 50\% under the displacement demand that typically occurs in a conventional earthquake

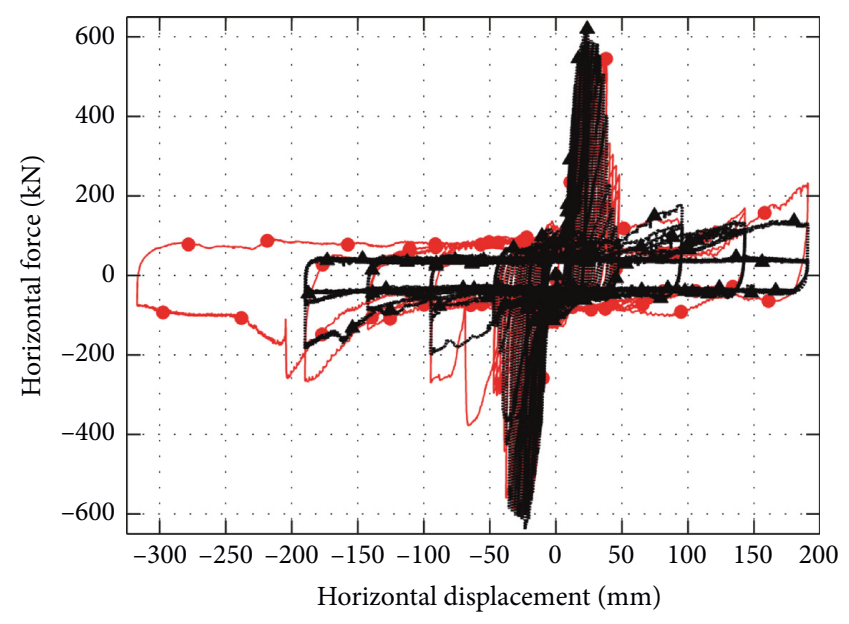

- Weak pintles, long

A. . Weak pintles, trans

(a)

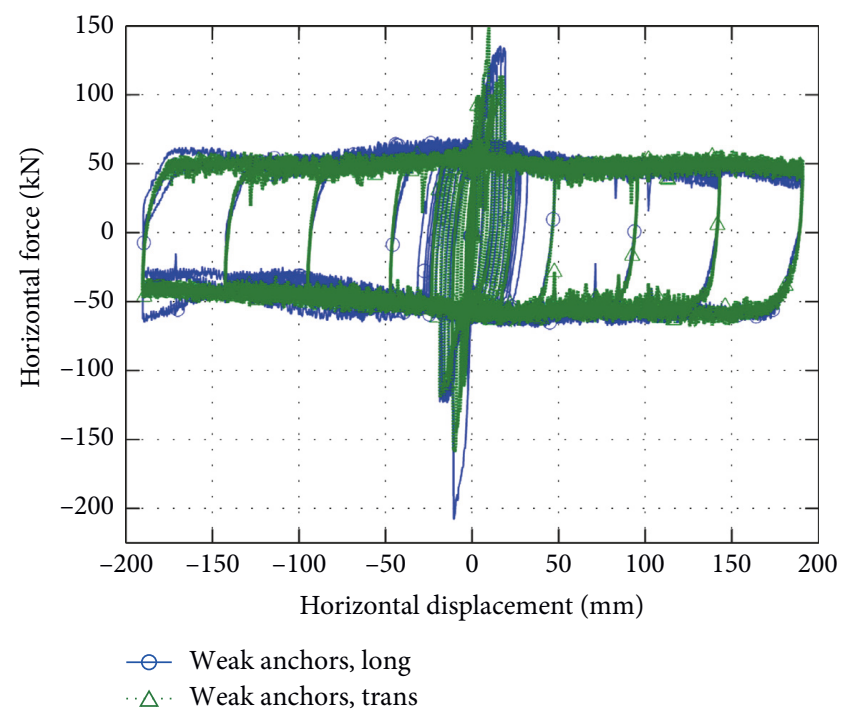

(b)

FIgURE 1: Results of complete weak (a) pintle and (b) anchor tests.

$[17,18]$. In addition, the height of the device including connecting elements is usually more than $1 \mathrm{~m}$, which is suitable for installation between the pylon girders and pier girders of cable-stayed bridges but difficult in continuous girder bridges. Chiarotto [19], taking the Caracas-Tuy Medio railway bridge as an example, examined the seismic performance of a combined cantilevered cylindrical damper with a fuse device using full-scale shaking table tests. Because of the presence of a cantilevered cylindrical damper, the vertical height of the support body was high, as shown in Figure 2, similar to that of triangular damper, limiting the engineering applications.

In this paper, a design criterion and a technical approach for the controlled seismic behavior of continuous girder bridges are proposed using the seismic design concept in which the bearings are used as "sacrificial elements." Specifically, a novel limited capacity isolation bearing with controllable performance and greater predictability than 


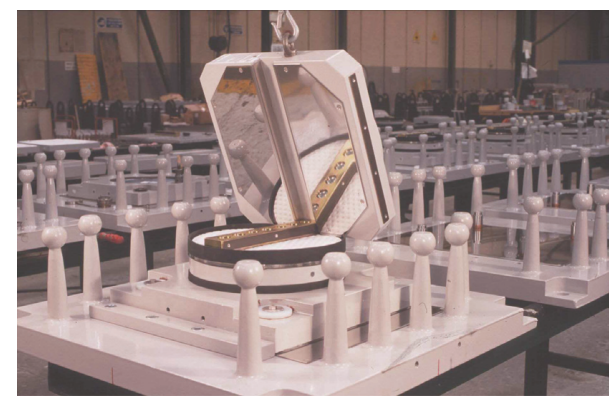

Figure 2: Steel damping bearings used in the Caracas-Tuy Medio bridge.

existing bearings is introduced. Two kinds of energy consumption devices for limiting the displacement according to the available installation space of different continuous girder bridges are presented. The mechanical behavior of the abovementioned seismic components was tested by experiment, and the constitutive model parameters were determined. A typical continuous girder bridge is used to demonstrate the design criteria and corresponding technical approaches discussed in this paper, which provides a reference for designers to carry out the seismic design of continuous girder bridges.

\section{Methods}

\subsection{Design Criterion for Controlled Behavior of Continuous Girder Bridges}

2.1.1. Characteristics of the Supporting System of Continuous Girder Bridge. When the supports of continuous girder bridge are arranged, the braking force, temperature force, and the horizontal force produced by the slope under the self-weight of the girder should be considered. Two kinds of supporting systems comprising conventional continuous girder bridges under normal and earthquake conditions are shown in Figure 3. In general, only one brake pier is set, and the others are moveable piers that are used to meet the extend-retract requirements of the girder at different temperatures. If the lateral spacing between the two supports of the same pier is large, one movable support in the transverse direction should be considered. To control the behavior of continuous girder bridges, the concept of "limited capacity" is proposed. This "limited capacity" is used mainly to meet the requirements of the normal use state of the bridge structure, for example, the horizontal force generated by the longitudinal slope of the girder and the braking force generated by vehicle transit, which result in certain requirements for the strength and stiffness of the supporting connection system. This demand is achieved through different arrangements and different numbers of steel pintles. Under the action of a strong earthquake, when the force exerted on the connecting element reaches or exceeds the "limited capacity," the pintle is cut and the brake pier is converted into a movable pier. In addition, the potential seismic performance of the moveable pier can be utilized to help the brake pier bear the seismic load by setting up the energy dissipation device on the corresponding movable pier, but the device on the movable pier should meet the extend-retract requirements of the girder.

2.1.2. Basic Description of the Criteria. On the basis of the characteristics of continuous girder bridges, the following criteria were defined: the main structures, such as the pier and pile foundation, should not show plastic deformation under the action of the isolation bearing, energy dissipation damper, or other limiting displacement devices. When the seismic energy is very large and the main structure may be destroyed, the main structure can be protected by sacrificing some components (such as bearings). Once the bearing is destroyed, the seismic displacement of the girder can be reduced by setting a sufficient lap length and coordinating with a series of large-stroke friction and energy dissipation devices to dissipate part of the vibration energy transmitted by the girder. In the design criterion, there are several key technologies that must be implemented, as listed below:

(i) The performance of the support system should meet the requirements of operation under normal conditions, including the vertical bearing force and the ability to adapt to the deformation of the girder.

(ii) The whole failure process of the connecting elements between the superstructure and substructure should be predictable, including that of the conventional bearings, isolation bearings, and energy consumption limit devices.

(iii) A reasonable classification and combination of proper elemental units is necessary. The failure order of the components must be controlled during earthquake, and the failure of any component should not lead to unpredictable seismic behavior in the bridge structure.

(iv) The effects of factors other than earthquakes on supporting systems should be reliably evaluated and guaranteed, such as vehicle braking load and typhoon load.

2.2. Technical Approach for Controlled Design. In this section, a novel isolation bearing and two kinds of large-stroke steel damping devices are introduced, respectively, from the perspectives of the partition of the seismic force and the control of displacement.

2.2.1. Configuration of the Isolation Bearing. The isolation bearing includes an upper plate, arced tetrafluoro plate, spherical crown, planar tetrafluoro plate, bottom plate, and limiting block. The limiting block is equipped with shear pintles, and the size and number of pintles are determined depending on the "limited capacity." The initial fixed direction is shown in Figure 4, where limiting blocks are arranged on both sides of the bottom plate of the bearing through the pintles. Under normal conditions, the translational displacement of this direction is constrained by the 


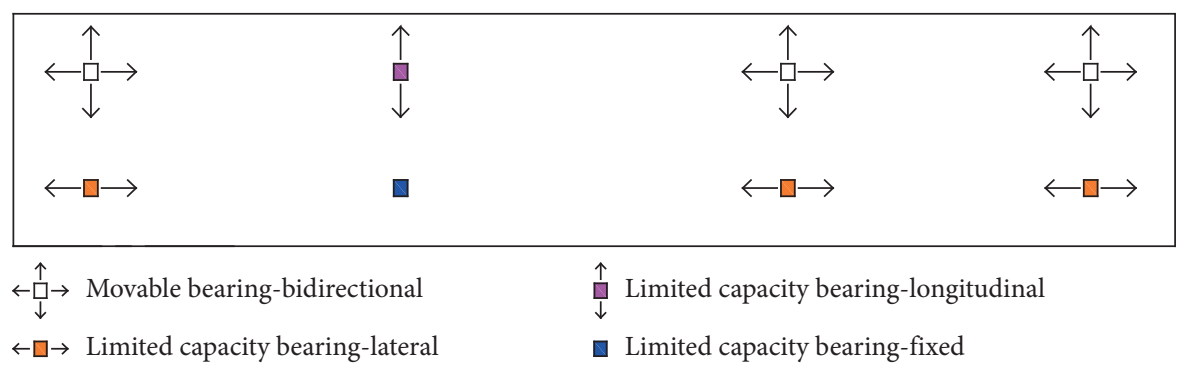

(a)

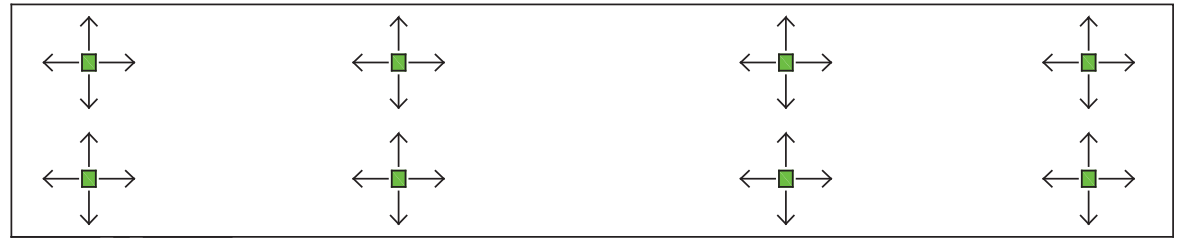

$\leftarrow \underset{\downarrow}{\uparrow} \rightarrow$ Friction and energy dissipation device

(b)

FIGURE 3: Support system for the continuous girder bridge under (a) normal and (b) earthquake conditions.

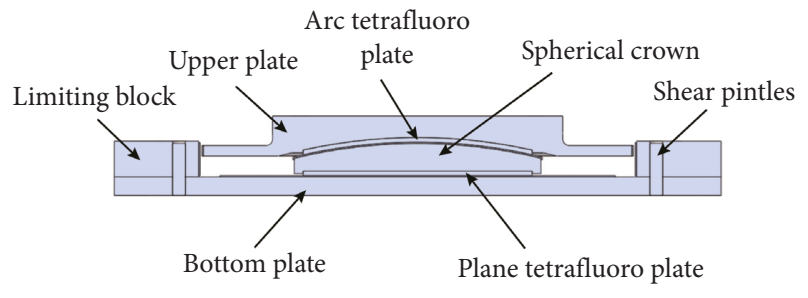

(a)

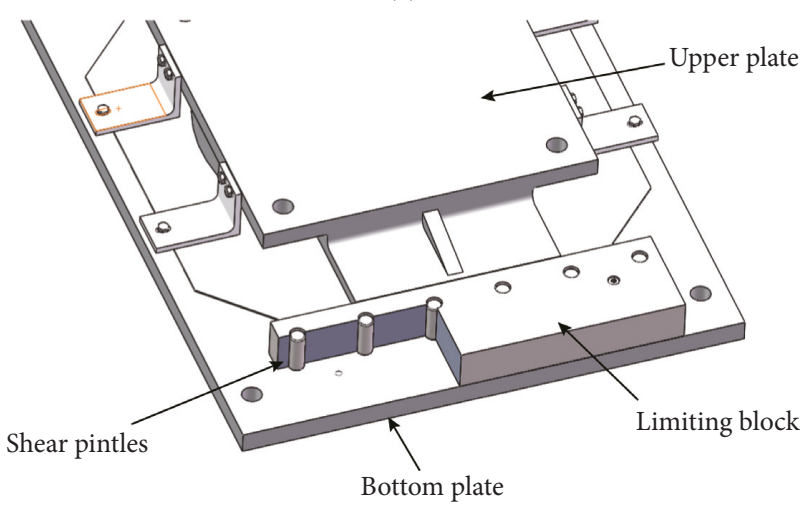

(b)

Figure 4: $(\mathrm{a}, \mathrm{b})$ Configuration of the isolation bearing.

limiting blocks. In the event of a large earthquake, when the seismic force of the limiting block exceeds the limited capacity, the shear pin is cut, and the spherical crown, together with the upper plate, undergoes translation slip friction on the sliding surface of the bottom plate, which greatly reduces the inertial forces transferred to the pier. Compared with the conventional bearing, the fracture of the pintles is arranged outside the range of the sliding friction surface, and the size of the preset friction surface can be flexibly adjusted by changing the cantilever length of the upper plate and the position of the limiting block. Compared with the condition where the shear pintles are located on the friction surface, the sliding behavior of the spherical steel bearing is more controllable and predictable.

\subsubsection{Configuration of the Large-Stroke Energy Dissipation Device}

(1) Cylindrical steel damping device: as shown in Figure 5 , the cylindrical steel damping device includes an upper plate, damping component, and bottom plate [20]. If used on the movable pier, a gap can be reserved between the top plate and the ball nose of the damping components to adapt to the extendretract requirements of the girder under different temperature conditions.

To ensure that the damping component yields simultaneously, a cantilevered column with varying cross-sectional diameter was chosen as the energyconsuming component, per the equal strain distribution principle. The corresponding design method equation is shown in the following equation [21]:

$$
\delta_{\max }=\frac{6}{5} \varepsilon_{\max }\left(\frac{32 F}{\pi \sigma_{y}}\right)^{-(1 / 3)} h^{(5 / 3)} .
$$

Here, $\delta_{\max }$ is the maximum stroke, $\varepsilon_{\max }$ is the maximum strain on the surface of the damper, $\sigma_{y}$ is the yield stress of the steel, and $h$ is the height of the damper.

(2) E-shaped steel damping device: the structural form of the E-shaped steel damping device is shown in Figure 6. A gap between the pin and the middle support can be reserved to adapt to the extend- 


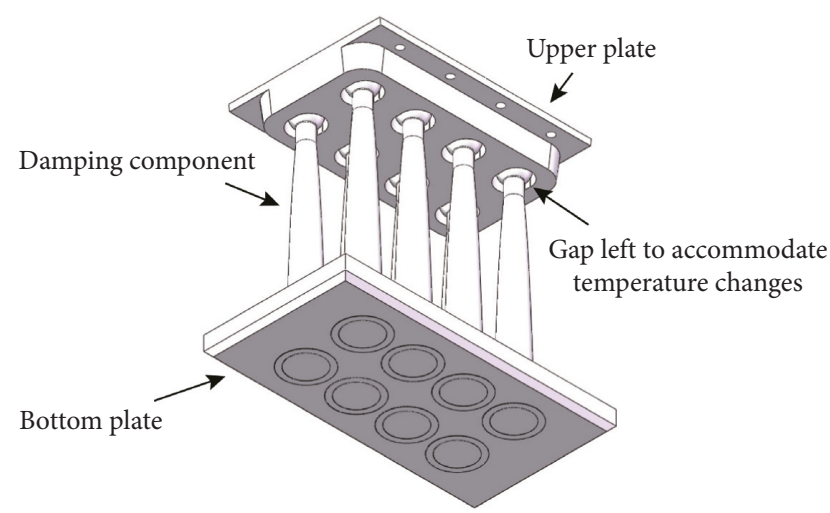

FIGURE 5: Configuration of the cylindrical damping device.

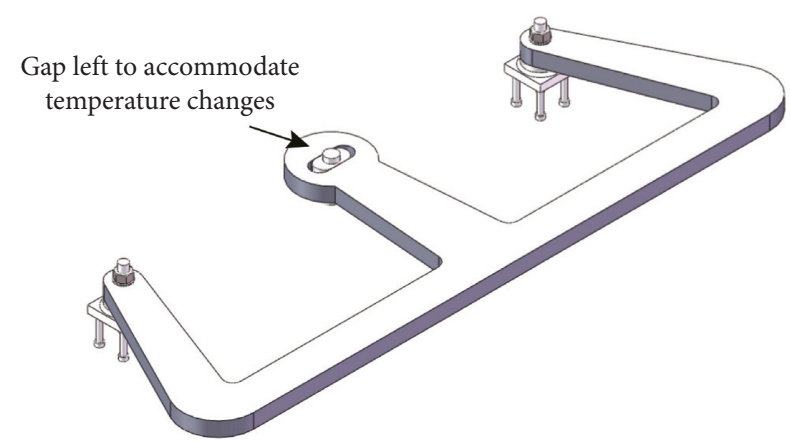

FIgURE 6: Configuration of the E-shaped damping device.

retract requirements of the girder under different temperature conditions [22].

The mechanical model of an E-shaped damper can be simplified as a beam model with two-hinged supports on both sides and one simple bearing as an intermediate support. The corresponding design method equation is shown in the following equation [23]:

$$
\delta_{\max }=2 \frac{h l}{b} \varepsilon_{\max }\left(1+\frac{\alpha}{2} \frac{h}{l} \frac{\varepsilon_{y}}{\varepsilon_{\max }}\right) .
$$

Here, $\alpha=2\left(b / b_{1}\right)^{3}+\left(b / b_{2}\right)^{3}, h$ is the height of the side support and middle support, $l$ is the length of the crossbeam, $b, b_{1}$, and $b_{2}$ are the widths of the crossbeam, middle support, and side support, respectively, and $\varepsilon_{y}$ is the yield strain on the surface of the damper.

(3) Combinations of the isolation bearings and energy dissipation devices: different combinations of the isolation bearings introduced in Section 2.2.1 titled "Configuration of the Isolation Bearing" and the large-stroke energy dissipation device introduced in Section 2.2.2 titled "Configuration of the LargeStroke Energy Dissipation Device" result in good adaptability when installed on a continuous girder bridge. The height of the cylindrical damper is $1420 \mathrm{~mm}$ and, thus, requires significant vertical installation space. For the loudspeaker-shaped piers with grooves at the top, a supporting system with a combination of vertical cylindrical steel damping device and isolation bearing are preferred, as shown in Figure 7(a). In a situation with insufficient vertical installation space, such as the urban viaduct illustrated in Figure 7(b), an E-shaped steel damping device or horizontal cylindrical steel damping device (the cylindrical damper is placed horizontally) can be selected.

\section{Results and Discussion}

3.1. Experimental Study of the Controllable Behavior System. In view of the abovementioned isolation bearing and energy dissipation limiting device, a series of mechanical property tests were carried out, including pintle shear tests, initial shear tests on the isolation bearing, friction tests on the bearing body, and full-scale quasistatic tests on the steel damping device.

3.1.1. Pintle Shear Tests. The purpose of this test is to obtain the shear force and displacement curve of the bearing pintles and investigate the pintle failure mode. The pintle material was processed Qt-500 nodular cast iron, and the pintles were manufactured by the Shanghai Research Institute of $\mathrm{Ma}$ terials. Two kinds of specimens were tested: six pintles having outer diameters (OD) of $20 \mathrm{~mm}$ and shear diameters of $12 \mathrm{~mm}$ and six pintles having outer diameters of $25 \mathrm{~mm}$ and shear diameters of $16 \mathrm{~mm}$, as shown in Figures 8(a) and 8 (b), respectively. The loading rate was divided into $0.01 \mathrm{~mm} / \mathrm{s}$ and $1 \mathrm{~mm} / \mathrm{s}$.

During the test, the actuator was loaded with a uniform displacement according to the specified loading rate, and the pintle fracture occurred via sudden brittle failure with a loud noise. The pintle was broken at the preset inner cut, and the fracture section was smooth, which is typical of shear failure. The pintles and fracture sections after the shear test are shown in Figure 9.

The results of the breaking force and fracture displacement of the pintle shear tests are summarized in Table 1.

The force-displacement curves of the pintles are shown in Figure 10. The shear curves of the pintles of the same size vary significantly, and there are two possible reasons for this. One is that the pintles were machined with low machining accuracy, resulting in deviations between pintles. Alternatively, the hole in the loading plate may be deformed by the repeated loading.

According to the data in Table 1 , the average breaking force of the $20 \mathrm{~mm}$ OD pintles is $43.27 \mathrm{kN}$ at the slow shear rate and $44.83 \mathrm{kN}$ at the rapid shear rate; the relative difference is $3.6 \%$. The average breaking force of the $25 \mathrm{~mm}$ OD pin is $70.78 \mathrm{kN}$ at the slow shear rate and $74.49 \mathrm{kN}$ at the rapid shear rate; the relative difference is $5.2 \%$. Thus, the shear capacity of the pintles increases with increasing loading rate. However, the increase is not significant within the range of loading rates reported in this paper. The forcedisplacement curves show that the mechanical behavior of the pintles under the same working conditions is relatively consistent; in particular, the breaking force and fracture 


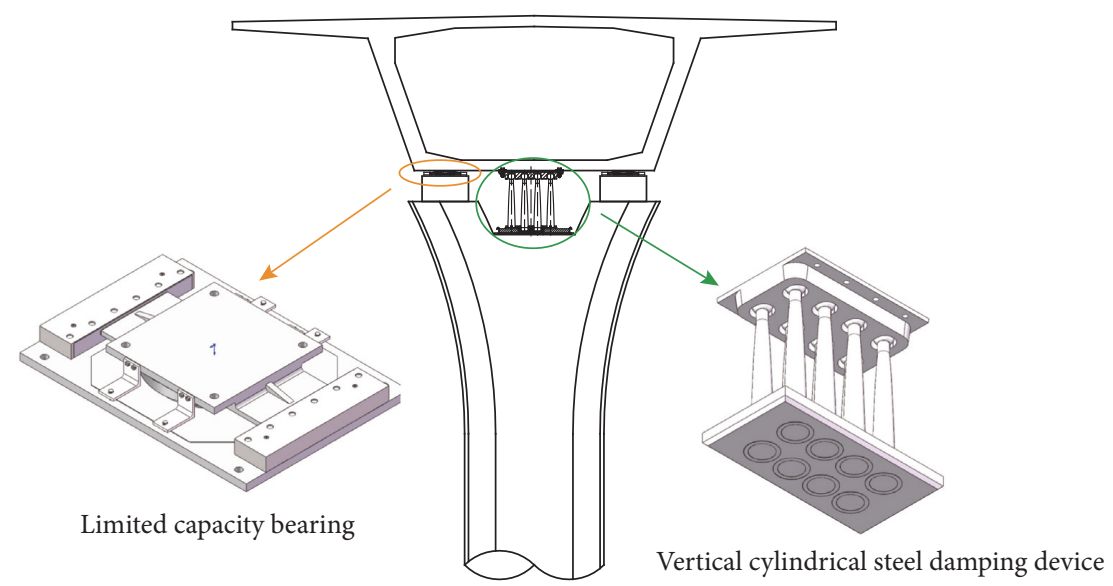

(a)

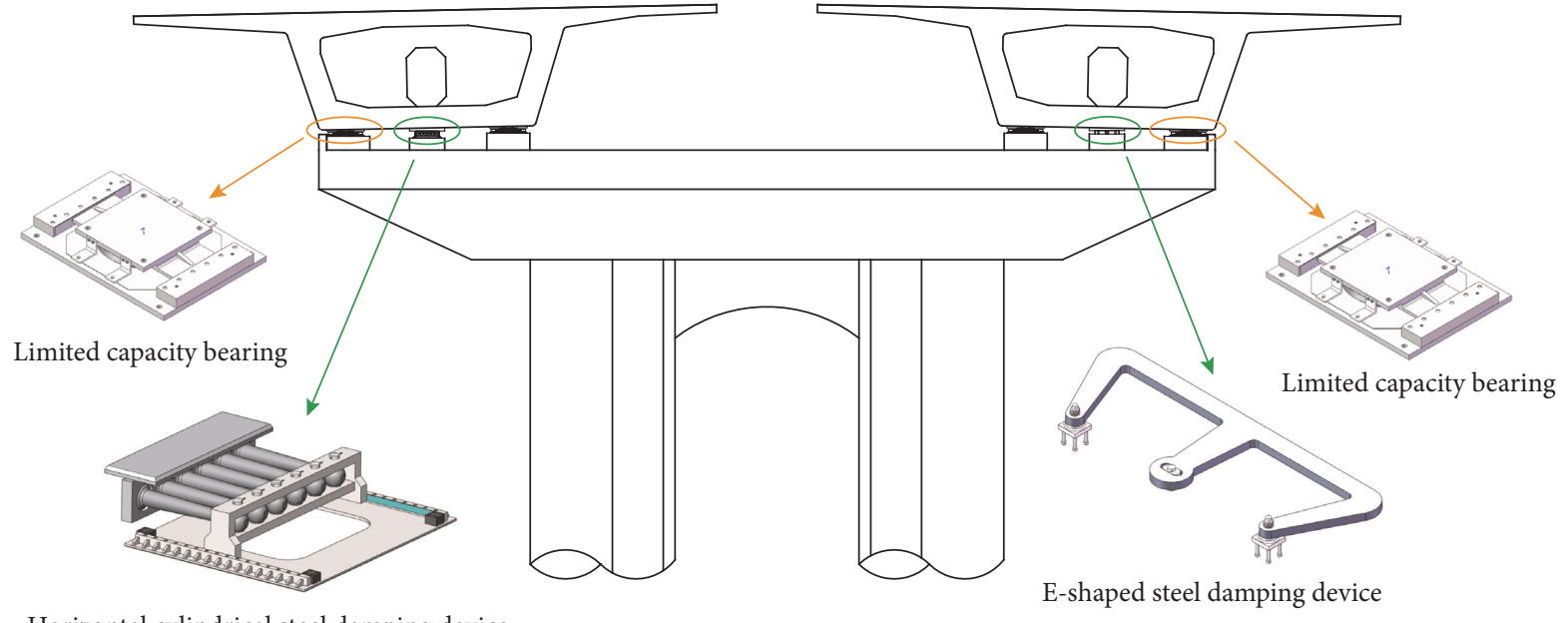

Horizontal cylindrical steel damping device

(b)

Figure 7: Combination of limited capacity bearings and different damping devices. (a) Limited capacity bearing + vertical cylindrical damping device. (b) Limited capacity bearing + E-shaped damping device or limited capacity bearing + horizontal cylindrical damping device.

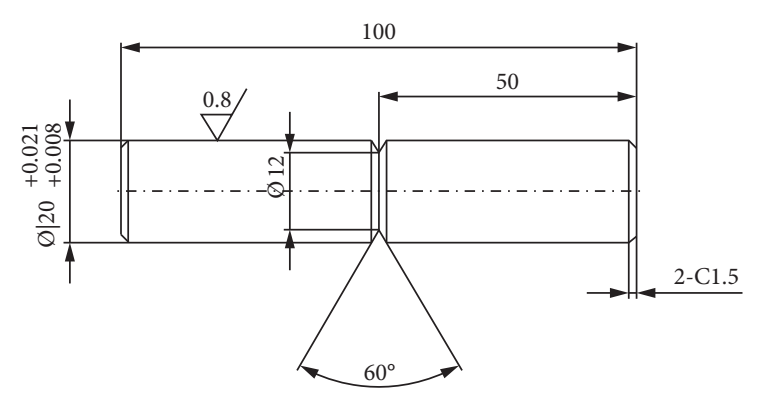

(a)

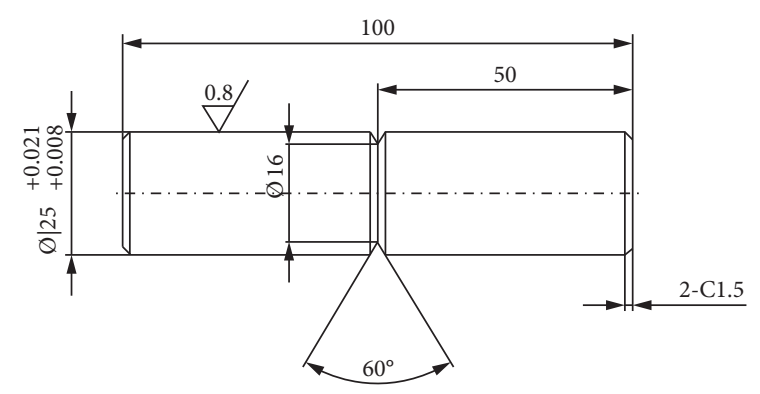

(b)

Figure 8: Configuration of pintles. (a) Outer diameter of $20 \mathrm{~mm}$ and shear diameter of $12 \mathrm{~mm}$. (b) Outer diameter of $25 \mathrm{~mm}$ and shear diameter of $16 \mathrm{~mm}$.

displacement curves are close, indicating that the failure mode of the pintles is stable.

3.1.2. Initial Shear Tests of the Isolation Bearing. The tests were carried out under a vertical pressure of $3000 \mathrm{kN}$. The horizontal loading was carried out at a constant rate of $0.02 \mathrm{~mm} / \mathrm{s}$ until the limiting block on one side was cut, and then, the speed was adjusted to $2 \mathrm{~mm} / \mathrm{s}$ and loaded to $10 \mathrm{~mm}$ (10\% of the horizontal deformation capacity of the bearing); then, the velocity was reloaded to $0.02 \mathrm{~mm} / \mathrm{s}$ to continue 


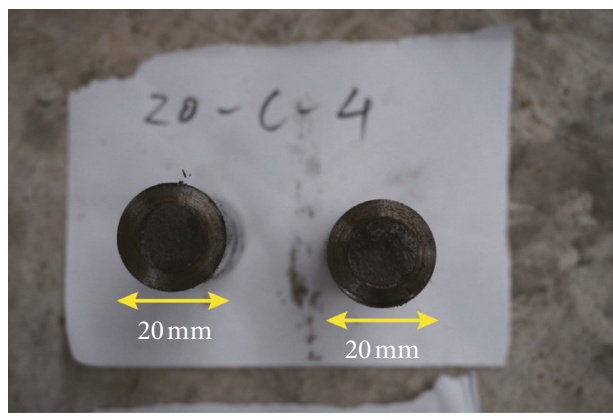

(a)

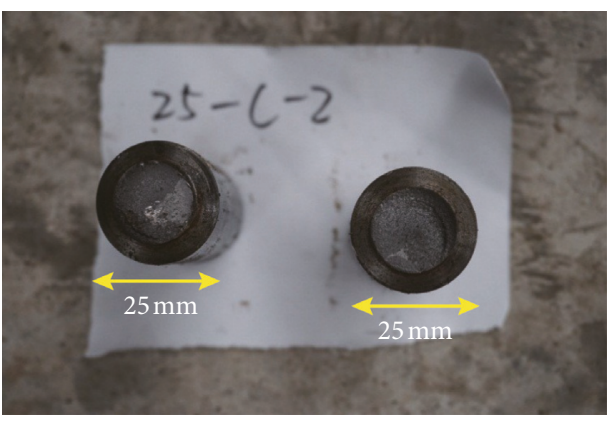

(b)

FIgure 9: Fracture morphology of the pintles. (a) Sample 20-C-4. (b) Sample 20-C-4.

Table 1: Pintle test results.

\begin{tabular}{lccc}
\hline Details & Specimen & Breaking force $(\mathrm{kN})$ & Fracture displacement $(\mathrm{mm})$ \\
\hline & $20-\mathrm{A}-1$ & 43.21 & 1.11 \\
$\varphi 20: 0.01 \mathrm{~mm} / \mathrm{s}$ & $20-\mathrm{A}-2$ & 42.66 & 1.14 \\
& $20-\mathrm{A}-3$ & 43.95 & 1.12 \\
& Mean value & 43.27 & 1.12 \\
\hline & $20-\mathrm{B}-1$ & 48.65 & 1.22 \\
$\varphi 20: 1 \mathrm{~mm} / \mathrm{s}$ & $20-\mathrm{B}-2$ & 44.10 & 1.22 \\
& $20-\mathrm{B}-3$ & 41.75 & 1.21 \\
& Mean value & 44.83 & 1.22 \\
& $25-\mathrm{A}-1$ & 67.35 & 1.38 \\
& $25-\mathrm{A}-2$ & 73.00 & 1.61 \\
& $25-\mathrm{A}-3$ & 71.99 & 1.62 \\
& Mean value & 70.78 & 1.54 \\
\hline & $25-\mathrm{B}-1$ & 76.26 & 1.64 \\
& $25-\mathrm{B}-2$ & 72.48 & 1.63 \\
& $25-\mathrm{B}-3$ & 74.74 & 1.69 \\
\end{tabular}

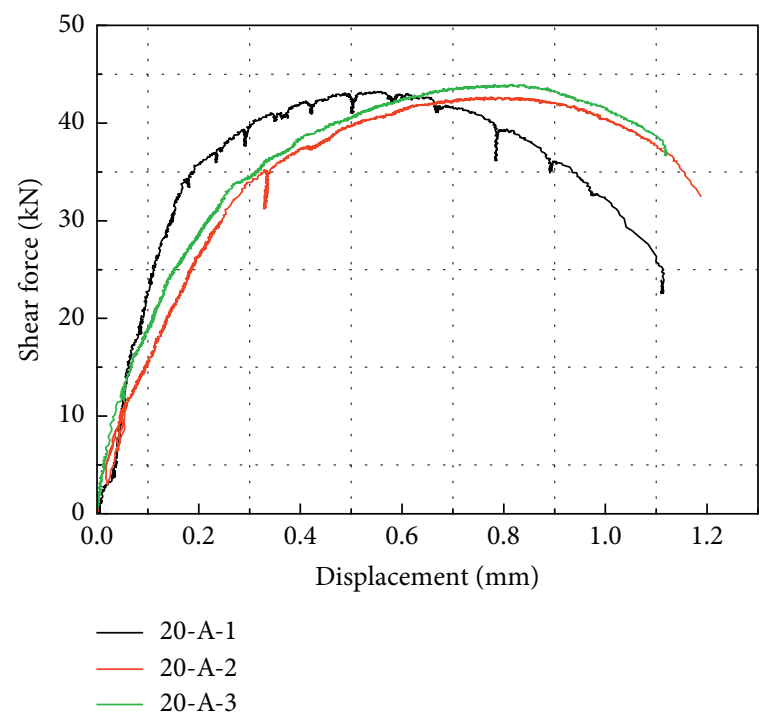

(a)

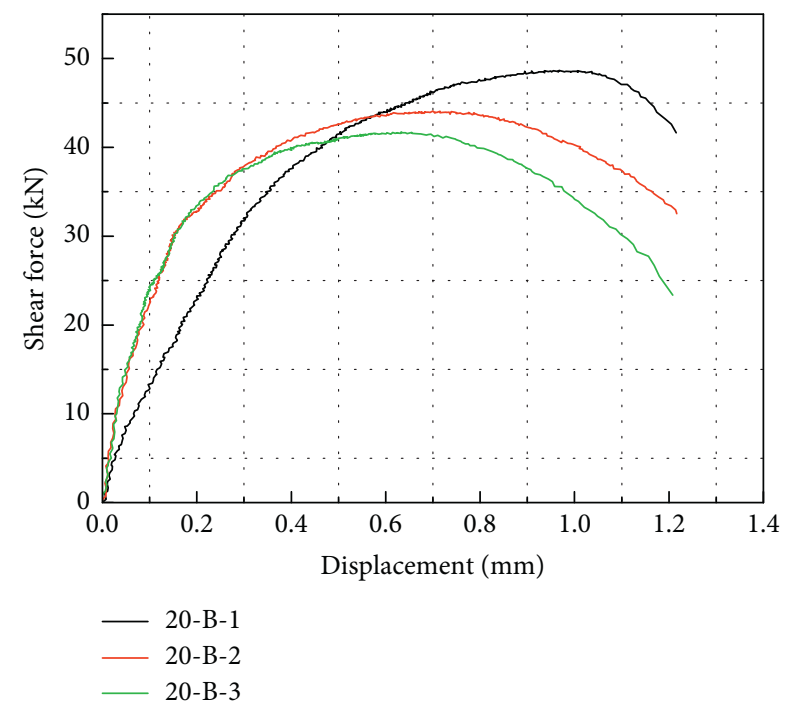

(b)

FIgURE 10: Continued. 


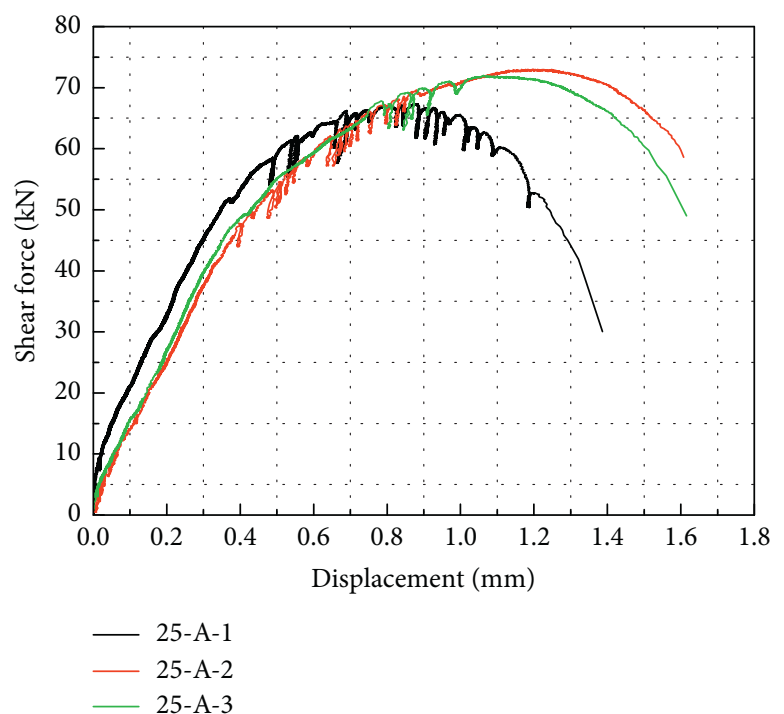

(c)

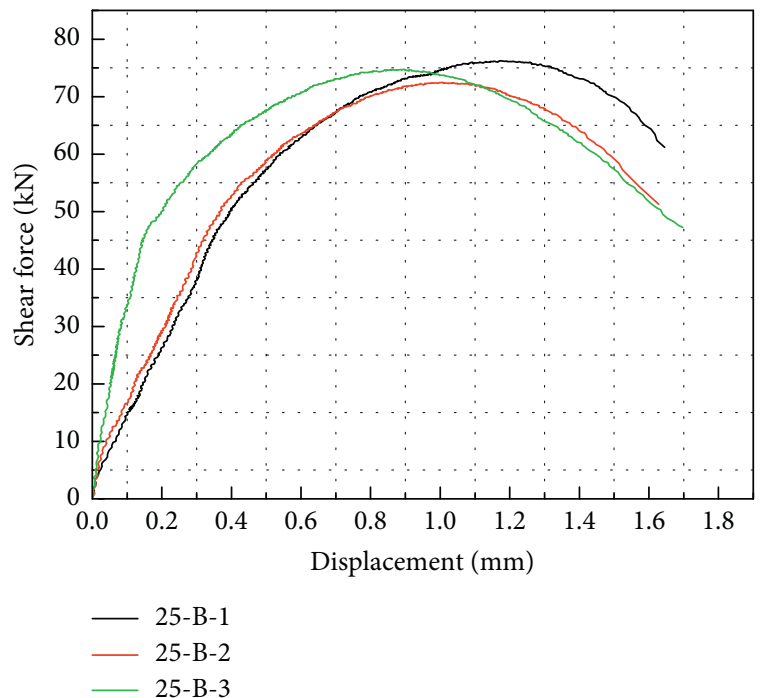

(d)

Figure 10: Pintle test curves. (a) $\varphi 20: 0.01 \mathrm{~mm} / \mathrm{s}$. (b) $\varphi 20: 1 \mathrm{~mm} / \mathrm{s}$. (c) $\varphi 25: 0.01 \mathrm{~mm} / \mathrm{s}$. (d) $\varphi 25: 1 \mathrm{~mm} / \mathrm{s}$.

loading until the limiting blocks on the other side were cut; finally, the speed was adjusted to $2 \mathrm{~mm} / \mathrm{s}$ and, subsequently, loaded to $10 \mathrm{~mm}$ to complete a reciprocating cycle. Then, three reciprocating cycles with peak displacements of $10 \mathrm{~mm}$ were completed at a constant rate of $2 \mathrm{~mm} / \mathrm{s}$. Photographs of the initial shear test are shown in Figure 11.

A linear model was established for the shear pin fractures. The linear model was built using the experimental origin and the fracture point plotted in Figure 12 as the limits. The six pintles (OD: $25 \mathrm{~mm}$ and shear diameter: $16 \mathrm{~mm}$ ) of the block on both sides were cut at the same time, resulting in overall shear failure and, thus, meeting the expected design target. The break forces on the left and right sides are similar 507 and $529 \mathrm{kN}$, respectively, a difference of $4 \%$. The fracture displacement of the limiting block is basically consistent with the shear test results of the pintle alone. The related literature shows that the linear equivalent model in Figure 12 has good simulation accuracy and is simple to implement [14].

3.1.3. Friction Tests on the Bearing Body. The tests were also carried out under a vertical pressure of $3000 \mathrm{kN}$. Five sinusoidal wave loading cycles were conducted in the test, having loading frequencies of $0.01,0.02$, and $0.05 \mathrm{~Hz}$. The bearing body was loaded with $\pm 25 \%, \pm 50 \%$, and $\pm 100 \%$ of the displacement amplitude (horizontal displacement/ bearing deformation capacity $\times 100 \%$ ). By reviewing the results of the horizontal reciprocating loading tests of the bearing body after limiting block failure, a bilinear model was obtained by assuming that the area enclosed by the test curve and that enclosed by an equivalent curve are equal, as shown in Figure 13. The primary equivalent process is as follows. First, the straight-line $\mathrm{ME}$ is drawn (E is the intersection point of the test curve and the horizontal axis), and a straight-line NF is then drawn on the condition that lines $\mathrm{ME}$ and $\mathrm{NF}$ are parallel ( $\mathrm{M}$ and $\mathrm{N}$ are the unloading points). Assuming the same enclosed area, the positions of $\mathrm{P}$ and $\mathrm{Q}$ are then determined.

The test curve and equivalent curve of the horizontal reciprocating loading test are shown in Figure 14. At the three loading frequencies, the bearing shows stable hysteresis. The controlled mechanical behavior of the limited capacity outlined in this paper is, thus, verified from the above test results.

Taking the loading frequency of $0.01 \mathrm{~Hz}$ as an example, the mechanical parameters of the isolated bearing obtained are shown in Table 2.

3.1.4. Test of Steel Damping Device. A variety of cylindrical and E-shaped damping devices with different tonnages can be prepared by the simple combination of standard damping components. Some examples are shown in Figure 15.

Each standard component is identical in mechanics. Thus, the full-scale tests of the cylindrical and E-shaped components can represent the overall mechanical behavior of the assembled device. Based on the same target parameters, the design yield force of the standard component is $250 \mathrm{kN}$, the design yield displacement is $30 \mathrm{~mm}$, and the design stroke $(\Delta d)$ is $300 \mathrm{~mm}$. Using equations (1) and (2), the dimensions of the two damping components were obtained, as shown in Figure 16. The specimens were manufactured by the Shanghai Research Institute of Material, and the damping steel had a yield strength of $345 \mathrm{MPa}$.

The experiments were conducted in the State Key Laboratory of Tongji University. Referring to Chinese Standard JT/T 843-2012 [24] for the design of elastic-plastic steel damping bearings for highway bridges in China, the lateral displacement loading pattern is $0.25 \Delta d, 0.5 \Delta d$, and $1.0 \Delta d$. Photographs of the cyclic loading tests are shown in Figure 17. 


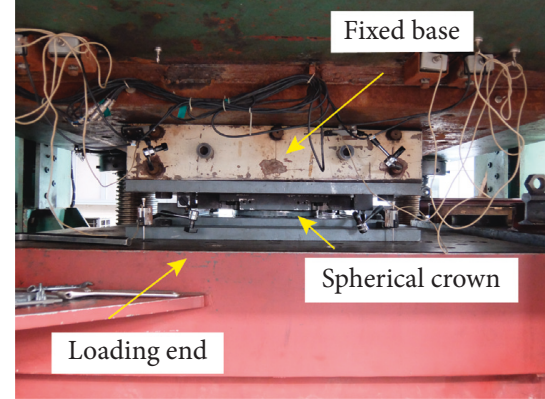

(a)

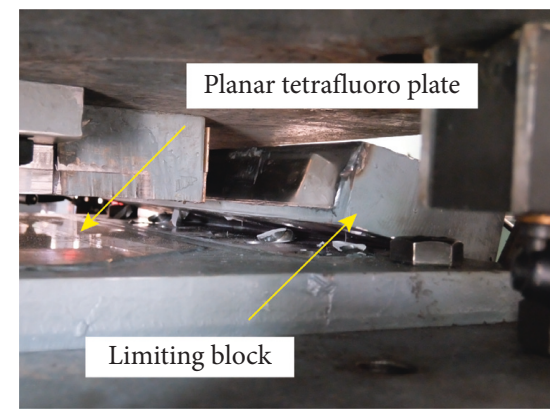

(b)

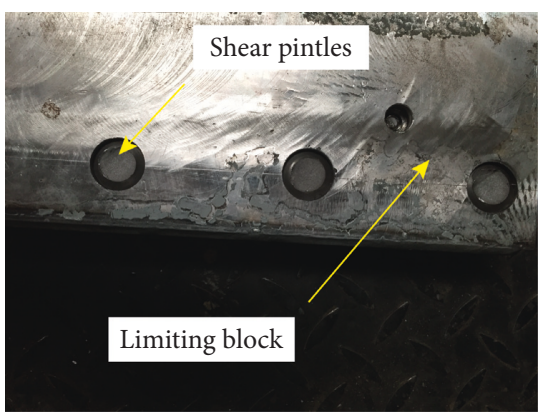

(c)

FIGURE 11: Photographs of the isolation bearing tests. (a) Limited capacity bearing. (b) Loading on the testing machine. (c) Limiting block.

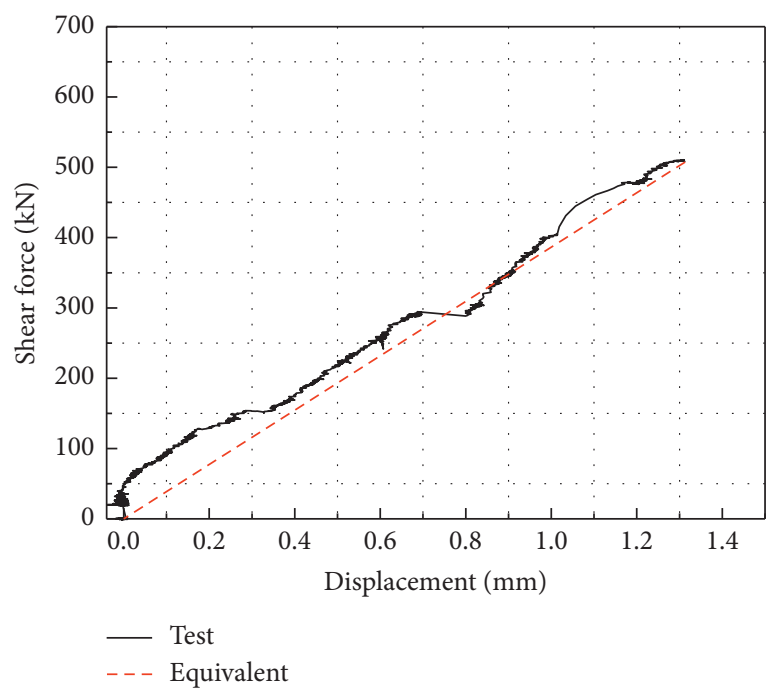

(a)

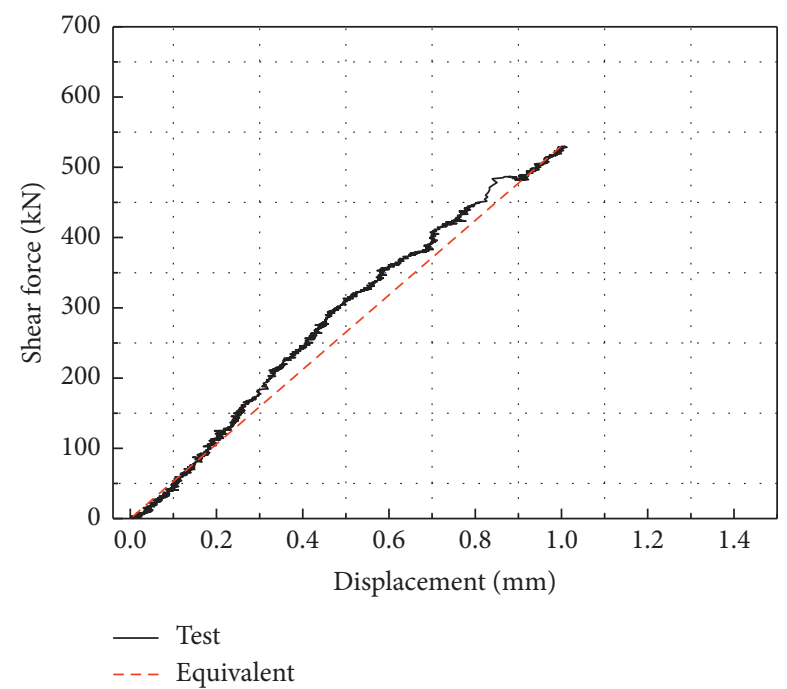

(b)

FIGURE 12: Initial shear test results. (a) Left limiting block. (b) Right limiting block.

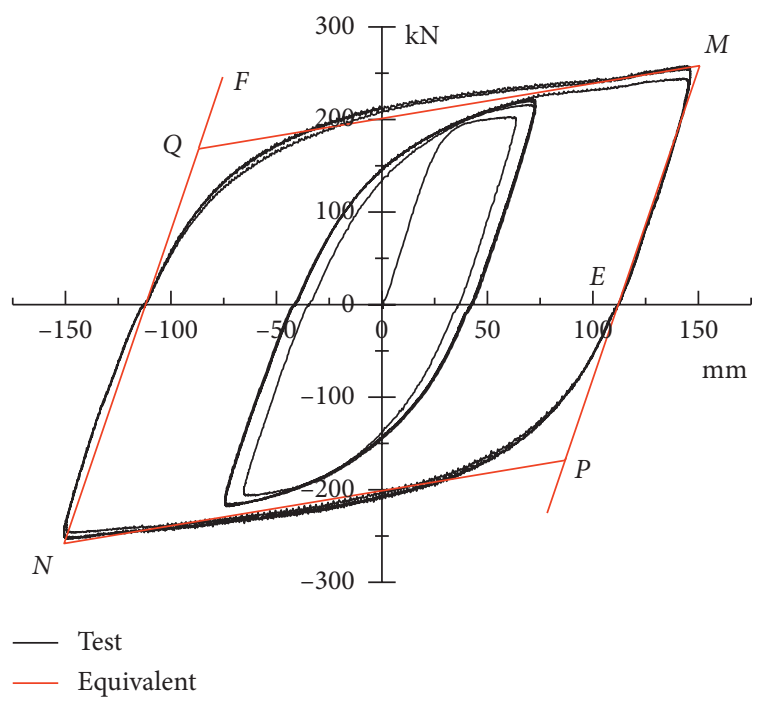

Figure 13: Schematic diagram of equivalent principle.

Upon conclusion of the test, there were no fractures or cracks in the damper and no failure in the other joint parts. The yield states of the third circle under the three displacement conditions are shown in Figure 18. The corresponding equivalent yield forces and yield displacements were obtained from a bilinear model on the basis of the equivalent principle shown in Figure 13, as presented in Table 3.

As listed in Table 3, the equivalent average force strength is $226 \mathrm{kN}$, the difference between the test and design value is $-9.5 \%$, the equivalent average yield displacement is $33 \mathrm{~mm}$, and the difference between the test and design value is $10 \%$. On the basis of these results, the deviation of all parameters is within $10 \%$. Thus, the parameters of the specimen comply with the expected design aims. The mean strength hardening coefficient under the three displacement conditions is $7.4 \%$. The maximum ductility coefficient of the two steel dampers, that is, the ratio of the maximum loading displacement ( $300 \mathrm{~mm})$ to the measured yield displacement $(33 \mathrm{~mm})$, is 9 . Importantly, when the damping element was loaded to $300 \mathrm{~mm}$, no damage to the damper occurred. In addition, the true maximum ductility coefficient will be higher.

\section{Case Study}

In this section, combined with a continuous girder bridge located in site II (sites I-IV range from stiff to soft in the 


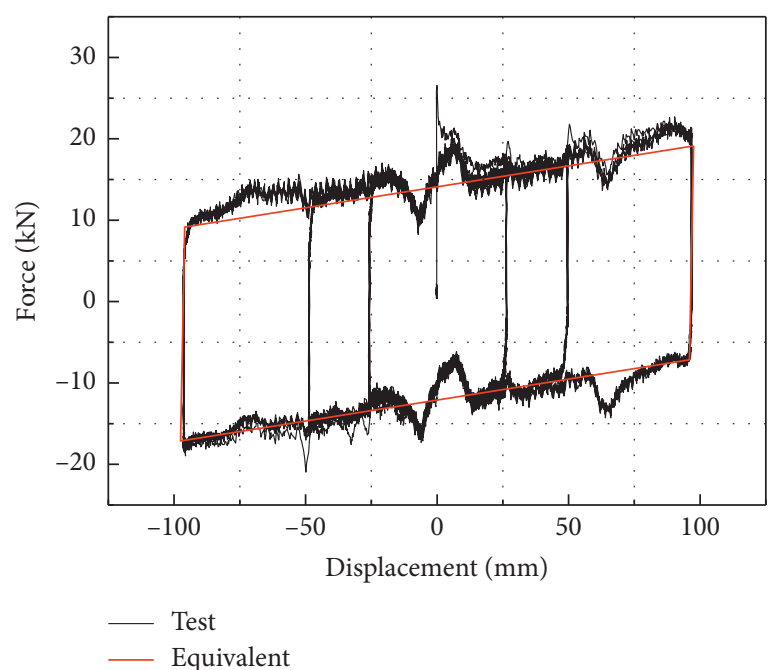

(a)

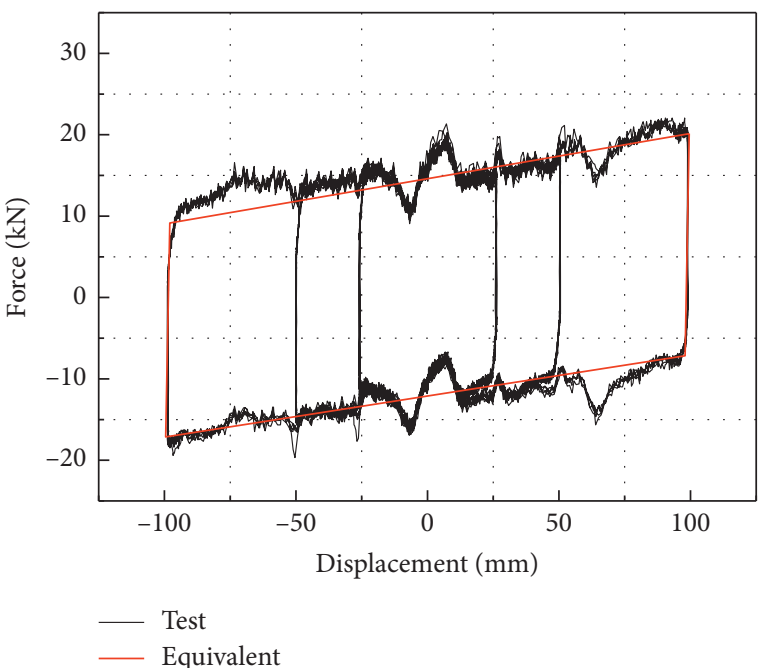

(b)

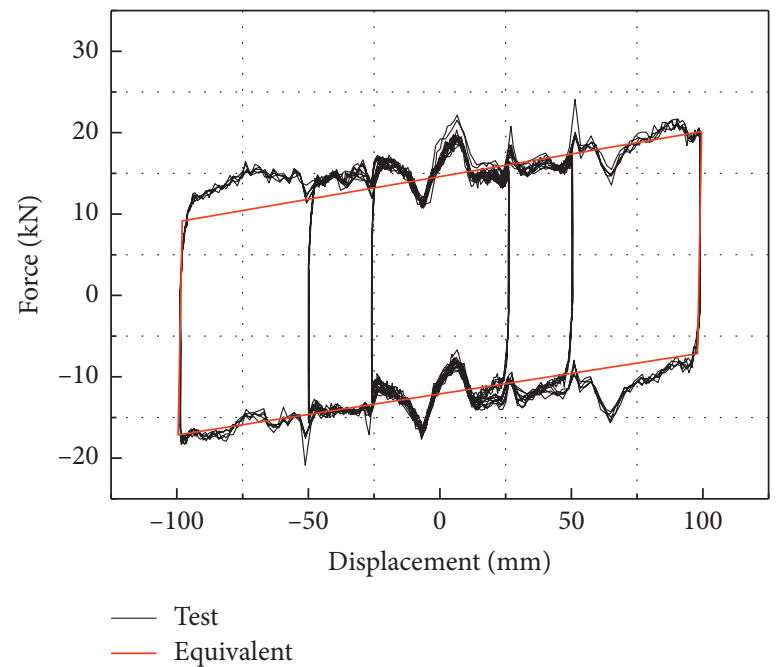

(c)

Figure 14: Friction test results of the bearing body. (a) 0.01 . (b) 0.02 . (c) $0.05 \mathrm{~Hz}$.

TABLE 2: Mechanical parameters of the limited capacity bearing.

\begin{tabular}{lc}
\hline Design parameters & Value \\
\hline Equivalent yield displacement $(\mathrm{mm})$ & 0.8 \\
Equivalent yield force $(\mathrm{kN})$ & 13.1 \\
Equivalent friction coefficient & 0.004 \\
Elastic stiffness, $K_{\mathrm{s} 1}(\mathrm{kN} / \mathrm{mm})$ & 16.6 \\
Postyield stiffness, $K_{\mathrm{s} 2}(\mathrm{kN} / \mathrm{mm})$ & 0.05 \\
Ratio of postyield stiffness to elastic stiffness & 0.003 \\
\hline
\end{tabular}

Chinese seismic specification) [25], the design criteria proposed in this paper are further verified and explained.

\subsection{Finite Element (FE) Model of a Continuous Girder Bridge.} The layout of the bridge is shown schematically in Figure 19. The shear resistance of the brake pier is $9.9 \mathrm{MN}$, and the bending resistance is $92.1 \mathrm{MN} \mathrm{m}$. There are five examples for calculation, as listed in Table 4 . In case (i), the brake pier is only equipped with the limiting capacity bearing. In cases (ii-iv), the brake piers are equipped with the limited capacity bearing and the energy consumption limiting device. Further, for cases (ii-iv), the fusing force is the same as that of case (i), and the designed yield forces of the steel damping device are 2500,5000 , and $7500 \mathrm{kN}$, respectively. In case (v), the brake pier is equipped with the conventional fixed bearing. In the above calculating cases, conventional sliding bearings are set on the rest piers (pier\#1, pier\#3, and pier\#4), and the value of the friction force is determined by multiplying the reaction force at the bottom of the girder by the friction coefficient obtained in the previous tests.

The girder, pier, and pile foundation were simulated using the elastic beam elements in Ls-dyna, and the grade of concrete was C40. Conventional fixed bearings were implemented using the keyword *MAT_SPRING_ELASTIC ( ${ }^{*}$ MAT_S01). The limited capacity was realized by combining the keywords MAT_ELASTIC_SPRING_DISCRETE _BEAM $\left({ }^{*}\right.$ MAT_074) and MAT_SPRING_GENERAL_ NONLINEAR( ${ }^{*}$ MAT_S06). The fusing behavior was realized 


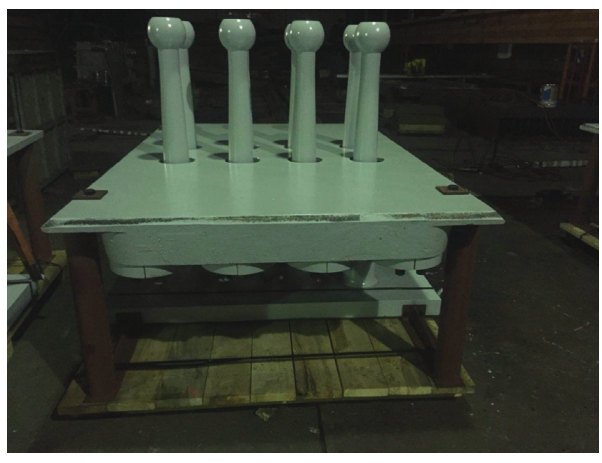

(a)

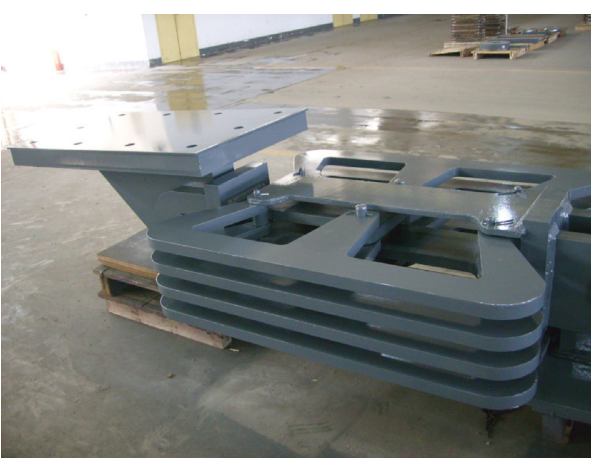

(b)

Figure 15: (a) Cylindrical and (b) E-shaped damping devices based on modular design.

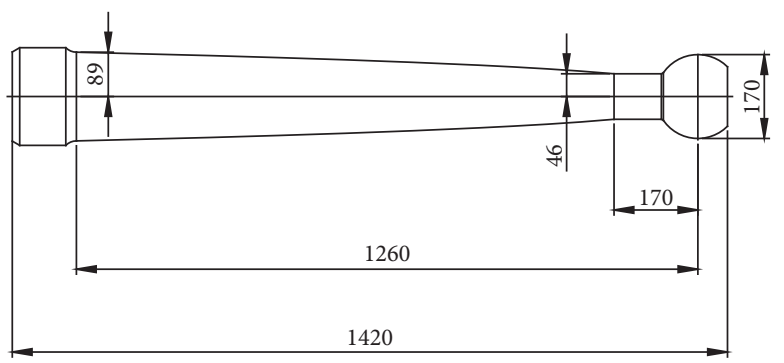

(a)

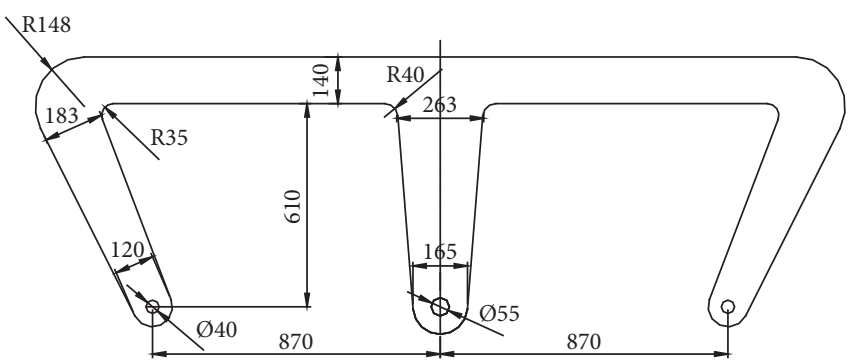

(b)

Figure 16: (a) Cylindrical and (b) E-shaped damper dimensions.

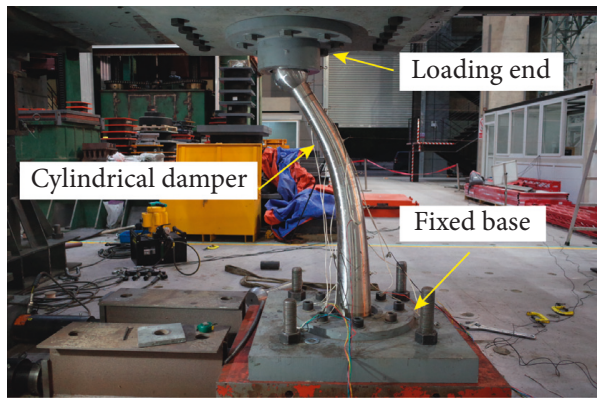

(a)

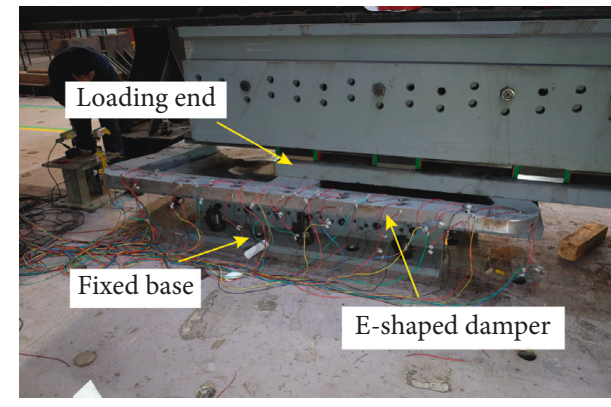

(b)

FIgUre 17: Photographs of the damper test. (a) Cylindrical. (b) E-shaped.

using the keyword *MAT_074, and the friction behavior after breaking was achieving using the keyword *MAT_S06. The hysteretic behavior of the movable bearing and steel damping device was simulated using a bilinear model achieved using the keyword *MAT_S06.

4.2. Seismic Input. To induce the fusing behavior of the bearing and the limiting effect of the steel damping device at the same time, the action of a large earthquake was used. The seismic hazards were determined per the design acceleration spectrum of the prototype bridge. A $4 \%$ probability of exceedance in 100 years was selected to represent high levels of seismicity. Table 5 provides information about the adopted ground motion excitations, which are available from the Pacific Earthquake Engineering (PEER) ground motion database. The acceleration spectrum for the selected earthquake is plotted against the Chinese seismic design code spectrum [25], as shown in Figure 20.

4.3. Calculation Results and Analysis. The forces of the brake piers in the five cases are listed in Table 6. 


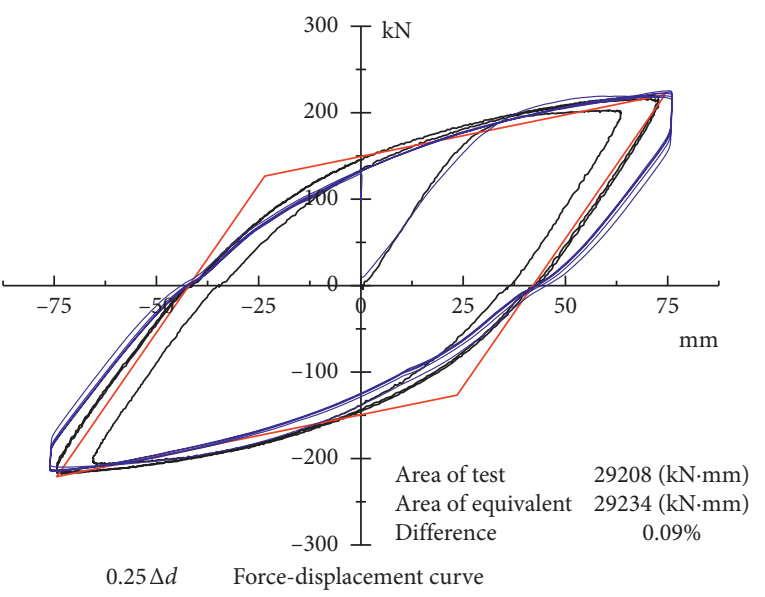

Test: cylindrical Test: E-shaped
Equivalent

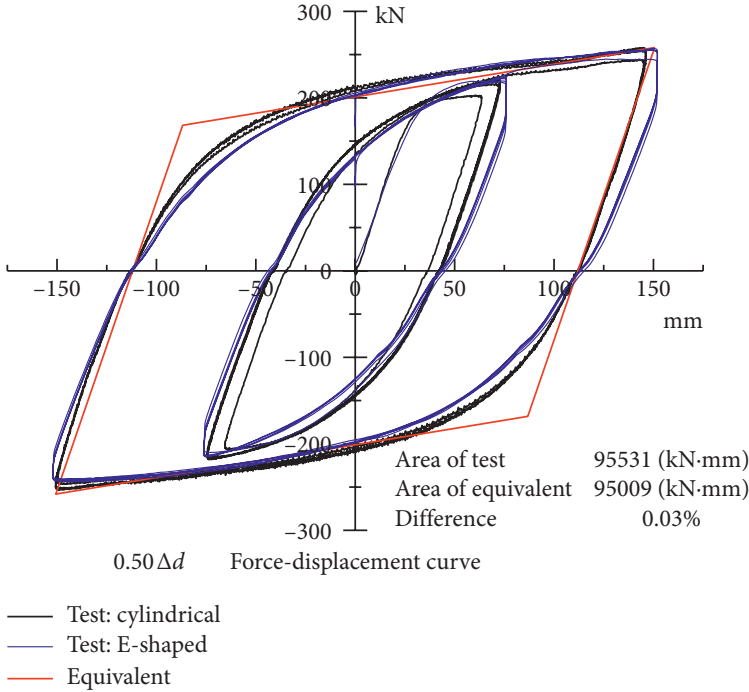

(b)

(a)

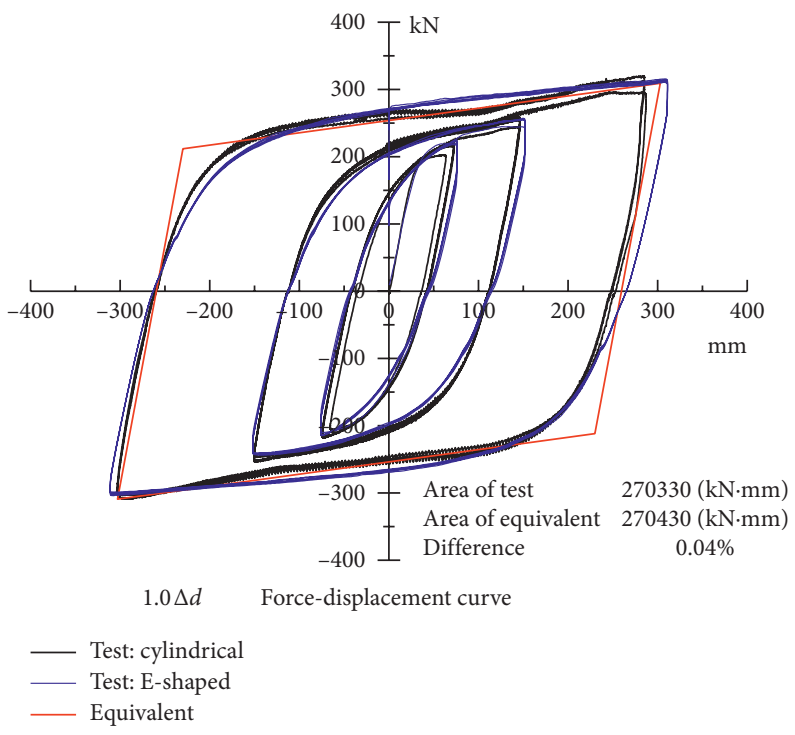

(c)

Figure 18: Test results. (a) 0.25. (b) 0. 5. (c) $1.0 \Delta d$.

Table 3: Deviation of mean value of third cycle yield state.

\begin{tabular}{lccc}
\hline & Yield force $(\mathrm{kN})$ & Yield displacement $(\mathrm{mm})$ & Strength hardening coefficient $(\%)$ \\
\hline Design value & 250 & 30 & - \\
Test value $( \pm 0.25 \Delta d)$ & 184 & 27 & 14.1 \\
Test value $( \pm 0.50 \Delta d)$ & 227 & 35 & 5.7 \\
Test value $( \pm 1.00 \Delta d)$ & 268 & 37 & 2.5 \\
Test value (average) & 226 & 33 & 7.4 \\
Average deviation $(\%)$ & -9.5 & 10 & - \\
\hline
\end{tabular}

Typical example time-history curves of the force and displacement are shown in Figure 21.

Concerning the force, when the conventional fixed bearing was used, the ratio of the shear response and capacity at the bottom of the brake pier was 0.91 and the ratio of the bending moment response to the capacity was 1.33 , which does not pass the validation calculation for bending resistance. If the limited capacity bearing is used (fuse moment at time $(t)=1.82 \mathrm{~s})$, the stress state of the pier should be significantly improved. When the limited capacity bearing was used alone, the ratio of the shear force and bending moment to the capacity were 0.17 and 0.23 , respectively. After adding the steel damping device, the ratio increased, as shown in Table 6. 


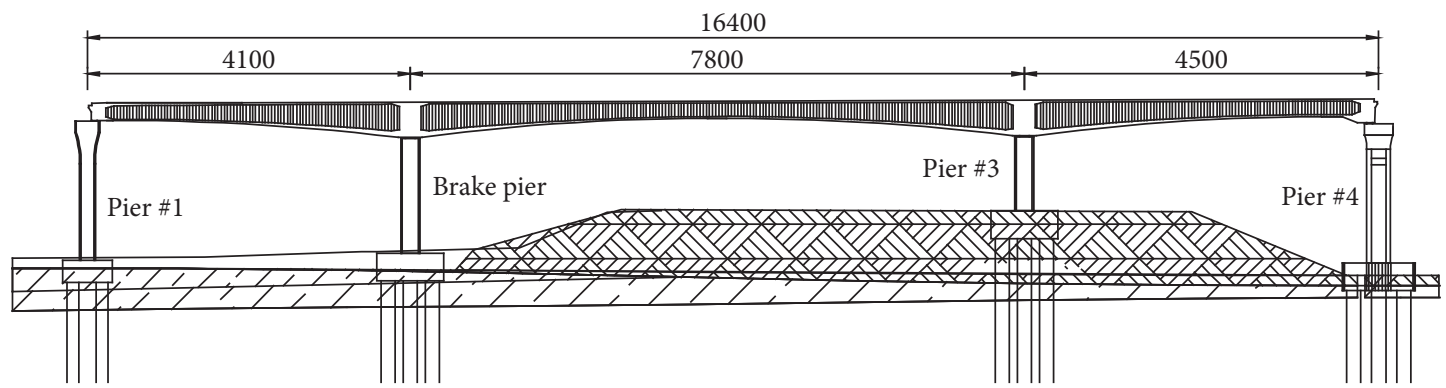

Figure 19: General layout of the bridge.

TABle 4: Cases for calculation.

\begin{tabular}{|c|c|c|c|c|}
\hline Case & Pier \#1 & Pier \#2 (brake pier) & Pier \#3 & Pier \#4 \\
\hline i & $\operatorname{csb} 1^{1}$ & $\mathrm{lcb}^{2}:$ limited capacity $=1800 \mathrm{kN}$ & $\operatorname{csb3}$ & $\operatorname{csb} 4$ \\
\hline ii & $\operatorname{csb} 1$ & $\begin{array}{l}\text { lcb: limited capacity }=1800 \mathrm{kN} ; \text { sdd }^{3}: \text { yield } \\
\text { force }=2500 \mathrm{kN}\end{array}$ & $\operatorname{csb} 3$ & $\operatorname{csb} 4$ \\
\hline iii & csb1 & $\begin{array}{l}\text { lcb: limited capacity }=1800 \mathrm{kN} \text {; sdd: yield } \\
\text { force }=5000 \mathrm{kN}\end{array}$ & $\operatorname{csb} 3$ & $\operatorname{csb} 4$ \\
\hline iv & csb1 & $\begin{array}{l}\text { lcb: limited capacity }=1800 \mathrm{kN} \text {; sdd: yield } \\
\text { force }=7500 \mathrm{kN}\end{array}$ & $\operatorname{csb} 3$ & $\operatorname{csb} 4$ \\
\hline $\mathrm{v}$ & csb1 & Fixed bearing & $\operatorname{csb} 3$ & $\operatorname{csb} 4$ \\
\hline
\end{tabular}

TABLE 5: Selected ground motion records.

\begin{tabular}{lccccc}
\hline Site & Earthquake & Year & Station & Component & PGA* (g) \\
\hline II & EL Centro & 1940 & El centro-lmp vall lrr dist & 180 & 0.21 \\
\hline
\end{tabular}

*Peak ground acceleration.

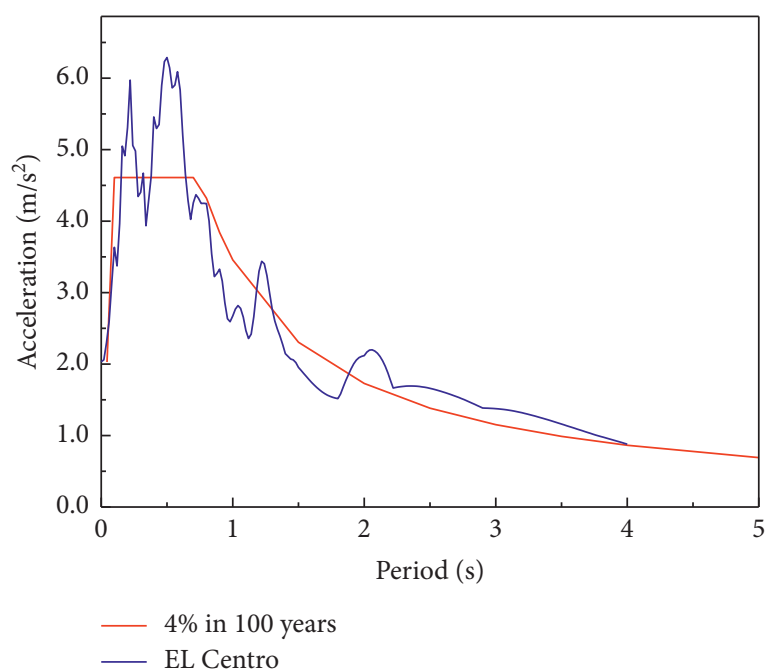

FIGURE 20: Comparison of the acceleration spectrum for the chosen earthquake data and the Chinese seismic code spectrum.

The displacement of key points under various cases are shown in Table 7.

With regard to the maximum displacement response, the relative displacement of the pier toward the girder increased significantly after the limited capacity bearing was used. For the brake pier (middle pier), the ratio of the maximum relative displacement to the deformation capacity is 0.41 after the $2500 \mathrm{kN}$ steel damping device was set. In the case of a $7500 \mathrm{kN}$ steel damping device, the ratio was 0.22 . The deformation of the damper in each calculated case is within the capacity range, as shown in Table 7. In addition, the relative displacement of the side pier toward the girder is particularly critical, and the possibility of girders falling off their supports should be considered. In the case where only the limited capacity bearing was used, the maximum displacement responses of the side pier toward the girder were 0.19 and $0.20 \mathrm{~m}$, respectively, and a proper lap length should be considered in the design.

Another issue that requires discussion is the residual displacement after an earthquake, which is a complex issue. When the designed yield forces of the steel damping device were 2500 and $5000 \mathrm{kN}$, the residual displacements were 0.09 and $0.02 \mathrm{~m}$, respectively. When a damping device with a higher capacity was installed, the residual displacement decreased further. However, at the same time, attention should be paid to the force response. For example, when the designed yield force of the steel damping device was $7500 \mathrm{kN}$, the ratio of the bending moment to the capacity reached 0.67. Referring to reference [26], if the residual displacement index is not ideal, the steel damping device can be set up on the other side piers. Thus, the seismic potential of the other piers can be utilized to consume energy and limit the girder displacement while not significantly increasing the seismic force of each pier. 
TABLE 6: Response of force of brake pier for the five cases.

\begin{tabular}{lcc}
\hline & Maximum shear/shear capacity & Maximum bending moment/bending capacity \\
\hline i & 0.17 & 0.23 \\
ii & 0.28 & 0.27 \\
iii & 0.36 & 0.47 \\
iv & 0.51 & 0.67 \\
v & 0.91 & 1.33 \\
\hline
\end{tabular}

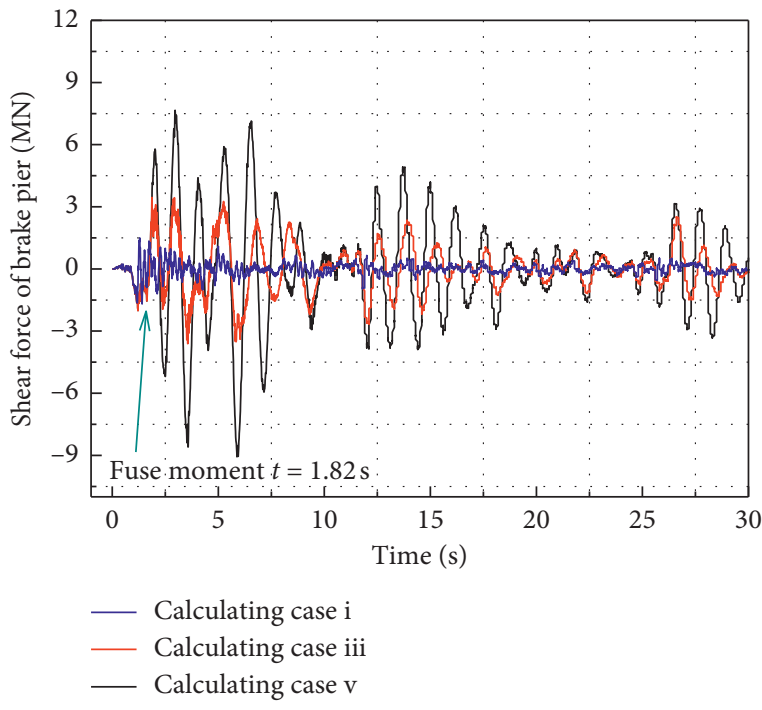

(a)

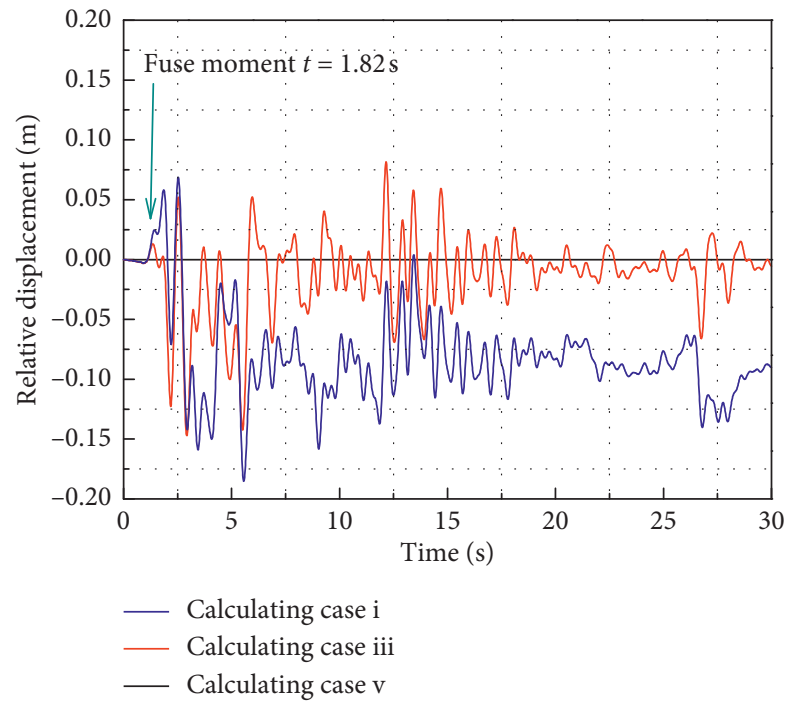

(b)

Figure 21: Seismic response for the cases I, iii, and $\mathrm{v}$ (the cases ii and iv are missing from this figure to clarify difference among the cases more clearly). (a) Shear force at the bottom of the brake pier. (b) Relative displacement of the side pier toward the girder.

TABLE 7: Displacement of key points in various cases.

\begin{tabular}{lcccc}
\hline & $\begin{array}{c}\text { Maximum deformation } \\
\text { of damper }\end{array}$ & $\begin{array}{c}\text { Maximum displacement of } \\
\text { damper/deformation capacity }\end{array}$ & $\begin{array}{c}\text { Maximum relative displacement of } \\
\text { the side pier \#1 toward girder }\end{array}$ & $\begin{array}{c}\text { Maximum relative displacement of } \\
\text { the side pier \#4 toward girder }\end{array}$ \\
\hline i & - & - & $0.19(0.09)$ & $0.20(0.09)$ \\
ii & $0.12(0.09)$ & 0.41 & $0.16(0.09)$ & $0.18(0.09)$ \\
iii & $0.08(0.02)$ & 0.28 & $0.15(0.01)$ & $0.16(0.02)$ \\
iv & $0.07(0.00)$ & 0.22 & $0.13(0.01)$ & $0.14(0.00)$ \\
v & - & - & $0.13(0.01)$ & $0.14(0.01)$ \\
\hline
\end{tabular}

Note. The use of parentheses () in the table indicates the residual displacement.

Based on the above results, when the fusing force of the limited capacity bearing is set at $1800 \mathrm{kN}$ and a $5000 \mathrm{kN}$ yield steel damping device is considered, a good balance between the force and displacement in the dynamic response can be achieved. The specific implementation can be realized by the combination of 24 pintles with a diameter of $25 \mathrm{~mm}$, as discussed in Section 3.1.1 titled "Pintle Shear Tests." The designed yield force of the steel damping device is $5000 \mathrm{kN}$. The specific implementation can be obtained by combining 20 cylindrical or E-shaped standard damping components in each section depending on the requirements of the actual installation space. Using this case (case iii) for calculation, the ratios of the shear force and bending moment to the capacity are 0.36 and 0.47 , respectively. Compared with the conventional fixed bearing, the shear force and bending moment are decreased by $60 \%$ and $53 \%$, respectively, and the pier is in an elastic state at this time. The ratio of the maximum deformation of the damper to its capacity is 0.28 , which yields a high safety factor. The residual displacement is $0.02 \mathrm{~m}$, which help ensure the postearthquake maintenance and replacement work. The specific response of the structure after setting a $5000 \mathrm{kN}$ yield force steel damping device is shown in Figure 22.

As reported previously [27], there are several uncertainties in the friction process, which may result in accidental bridge damage. The new type of bearings in this paper provides more controllable friction pairs and limits the unstable friction behavior in the bearings. At the same time, the isolation system is equipped with large-stroke steel damping device so that the energy dissipation capacity of the isolation system is sufficient, and thus, the seismic safety of the bridge is ensured. However, because of the 


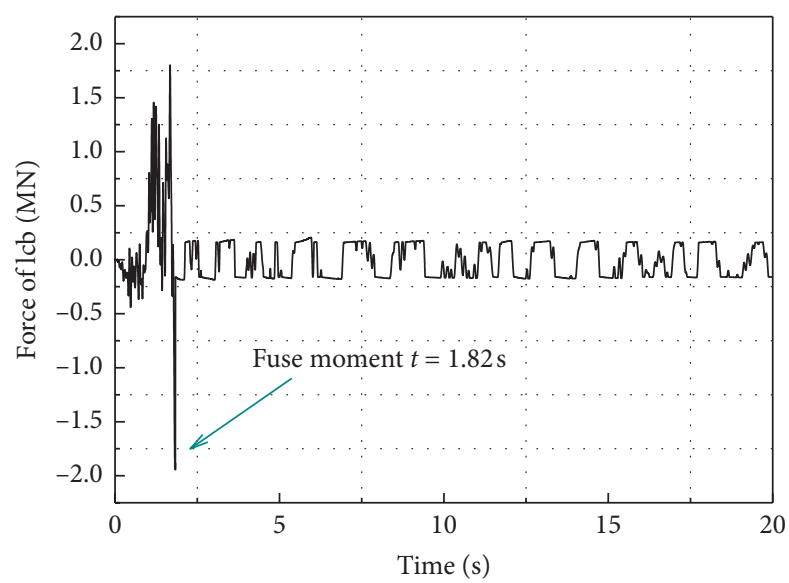

(a)

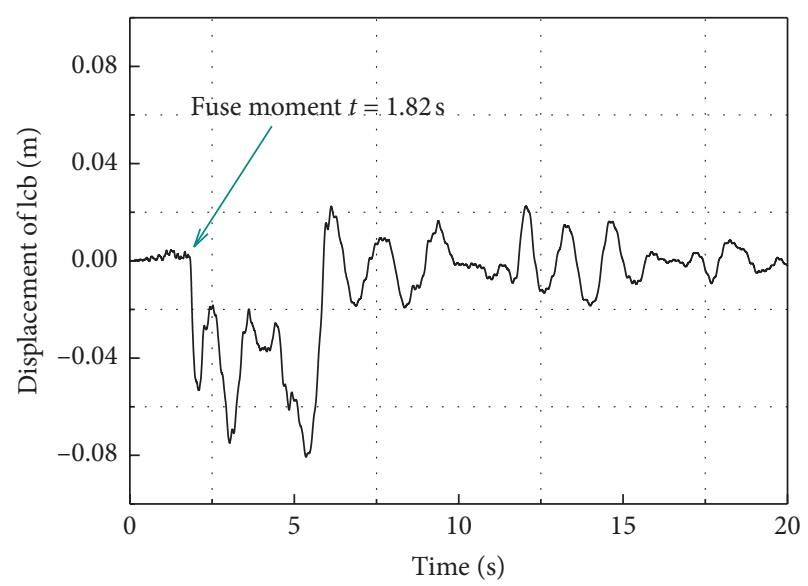

(b)

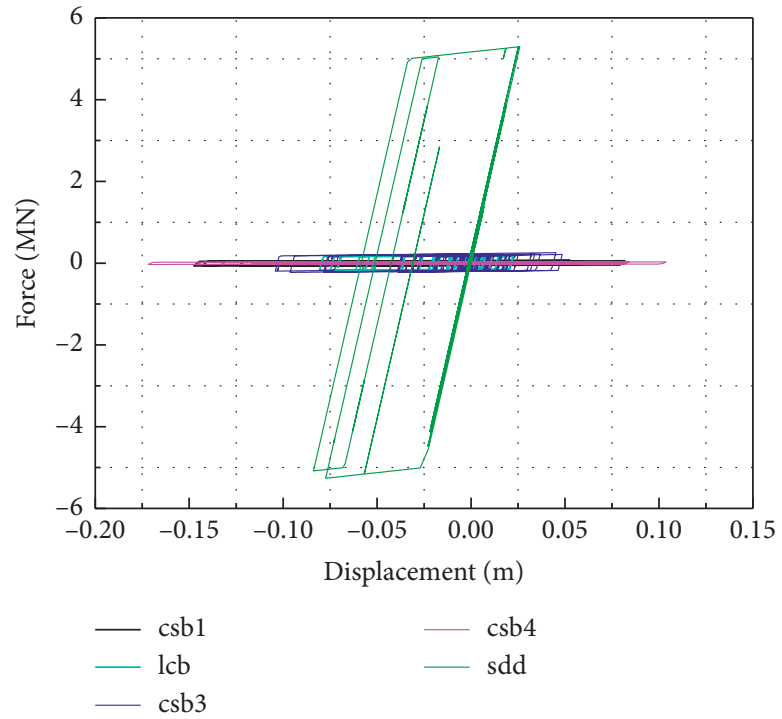

(c)

FIGURE 22: Seismic response of the bridge after the addition of a $5000 \mathrm{kN}$ yield force steel damping device. (a) The shear force of the limited capacity bearing. (b) Displacement of the limited capacity bearing. (c) Force versus displacement of the bearing and energy dissipation limiting device.

highly uncertain seismic loads, follow-up large-scale shaking table tests and actual seismic damage inspection are required to ensure the controllable seismic behavior of the bridge, and further continuous and in-depth research is ongoing. The discussed seismic design strategies are also applicable for improving the transverse seismic performance of bridges. When the limited capacity bearing is fused, the steel damping device in the direction of the transverse bridge acts as a limit. In fact, because the cylindrical damper has a circular cross section, the damping components have the same mechanical behavior in all directions on the plane. Therefore, one cylindrical steel damper can provide a bidirectional damping force in the longitudinal and lateral directions simultaneously. For other types of steel dampers such as E-shaped dampers, to provide a bidirectional damping force, the dampers should be matched with a bearing guiding system in two orthogonal directions.

\section{Conclusions}

Continuous girder bridges are the most widely used smalland medium-span bridge type in China. Consequently, it is of great economic and social significance to ensure their seismic safety. According to the characteristics of the supporting system of continuous girder bridges, a controlledbehavior design criterion was determined and a corresponding technical approach for continuous girder bridges was developed. A series of mechanical performance tests of the isolation bearing and energy dissipation limiting device were conducted. Finally, a continuous girder bridge was used as an example to verify the effectiveness of the design criterion proposed in this paper. The main conclusions are as follows:

(i) The controlled-behavior design criterion for a continuous girder bridge proposed in this paper is expressed as follows: The bearing is allowed to be 
destroyed as a "sacrificial unit" to release the seismic force of the superstructure and ensure that no damage occurs to the piers and piles, and a largestroke steel energy dissipation limiting device is also added to ensure that the relative displacement of the pier toward the girder is limited to an acceptable range. For the example bridge, when the fusing force of the limited capacity bearing was set at $1800 \mathrm{kN}$ and a $5000 \mathrm{kN}$ yield steel damping device was considered, a good balance between the force and displacement in the dynamic response was achieved. In particular, the ratios of the shear force and bending moment to the capacity were 0.36 and 0.47 , respectively, and the ratio of the maximum deformation of the damper to its capacity was 0.28 . Thus, the bridge performance under earthquake conditions was significantly improved.

(ii) A new type of isolation bearing has been designed, and the pintles, the limiting block, and the bearing body have been tested separately. The test results show that the shear process is highly controllable, and the friction behavior after fracture is highly stable with little unpredictability.

(iii) On the basis of the space requirements of the continuous girder supporting connection system, two kinds of large-stroke steel damping devices were designed, and mechanical property tests were carried out. The test results show that the hysteretic behavior of the two energy consumption limiting devices is basically the same based on the same target parameters. Thus, engineering designers can choose different steel damping devices according to the field conditions of the bridge project.

(iv) Numerical simulation shows the feasibility of our technical approach based on our criterion and provides a reference for designers to determine parameters such as the fuse force and yield force of energy dissipation limiting devices in the design of continuous girder bridges. For case studies, the addition of a steel damping device is helpful to reduce the residual displacement after the fusing of the limited capacity bearing. When the pier remains elastic, the residual displacement can be reduced to $0.01 \mathrm{~m}$.

With continued accumulation of knowledge concerning seismic damage phenomena and subsequent shaking table tests, the quantitative description of the FE model calculation results of the case study can be further verified. This is an ongoing process and requires more in-depth research.

\section{Data Availability}

The data used to support the findings of this study are available from the corresponding author upon request.

\section{Conflicts of Interest}

The authors declare that there are no conflicts of interest regarding the publication of this paper.

\section{Acknowledgments}

This study was supported by the National Key Basic Research Program (Grant Number: 2018YFC1504306), the National Science Foundation of China (Grant Numbers: 51438010 and 51778498), and the Research Program of the Shanghai Science and Technology Commission (Grant Number: 17DZ1204300).

\section{References}

[1] L. Fan and J. Li, "Earthquake damage analysis and seismic design countermeasures of Wenchuan bridge," Highway, vol. 5, pp. 122-128, 2009, (in Chinese).

[2] N. Xiang, M. S. Alam, and J. Li, "Shake table studies of a highway bridge model by allowing the sliding of laminatedrubber bearings with and without restraining devices," Engineering Structures, vol. 171, pp. 583-601, 2018.

[3] N. Xiang and J. Li, "Experimental and numerical study on seismic sliding mechanism of laminated-rubber bearings," Engineering Structures, vol. 141, pp. 159-174, 2017.

[4] N. Xiang and J. Li, "Seismic performance of highway bridges with different transverse unseating-prevention devices," Journal of Bridge Engineering, vol. 21, no. 9, Article ID 04016045, 2016.

[5] J. Li, N. Xiang, H. Tang, and Z. Guan, "Shake-table tests and numerical simulation of an innovative isolation system for highway bridges," Soil Dynamics and Earthquake Engineering, vol. 86, pp. 55-70, 2016.

[6] J. Li and H. Tang, "Study on transverse seismic design of small and medium span bridges with elastomeric bearing pads," Tumu Gongcheng Xuebao/China Civil Engineering Journal, vol. 49, no. 11, pp. 69-78, 2016.

[7] D. H. Tobias, J. F. Hajjar, R. E. Anderson et al., "Development and refinement of Illinois' earthquake resisting system strategy," in Proceedings of the 25th US-Japan Bridge Engineering Workshop, Public Works Research Institute, Tsukuba, Japan, October 2009.

[8] D. H. Tobias, R. E. Anderson, C. E. Hodel, W. M. Kramer, R. M. Wahab, and R. J. Chaput, "Overview of earthquake resisting system design and retrofit strategy for bridges in Illinois," Practice Periodical on Structural Design and Construction, vol. 13, no. 3, pp. 147-158, 2008.

[9] California Department of Transportation, Caltrans Seismic Design Criteria Version 17, California Department of Transportation, Sacramento, CS, USA, 2013.

[10] J. Zhuang, Bridge Bearing, China Railway Press, Beijing, China, 2008.

[11] E. T. Filipov, J. R. Revell, L. A. Fahnestock et al., "Seismic performance of highway bridges with fusing bearing components for quasi-isolation," Earthquake Engineering \& Structural Dynamics, vol. 42, no. 9, pp. 1375-1394, 2013.

[12] E. T. Filipov, L. A. Fahnestock, J. S. Steelman, J. F. Hajjar, J. M. LaFave, and D. A. Foutch, "Evaluation of quasi-isolated seismic bridge behavior using nonlinear bearing models," Engineering Structures, vol. 49, pp. 168-181, 2013.

[13] J. S. Steelman, E. T. Filipov, L. A. Fahnestock et al., "Experimental behaviour of steel fixed bearings and implications for seismic bridge response," Journal of Bridge Engineering, vol. 19, no. 8, Article ID A4014007, 2013.

[14] T. Peng and N. Guo, "An equivalent linear model for shear pin fractures and its experimental verification," Journal of Vibroengineering, vol. 18, no. 8, pp. 5281-5290, 2016. 
[15] T. Peng and N. Guo, "Experimental and numerical studies of shear pin fractures based on linear and bilinear models," Mechanics, vol. 22, no. 4, pp. 245-250, 2016.

[16] L. Zhou, X. Wang, and A. Ye, "Shake table test on transverse steel damper seismic system for long span cable-stayed bridges," Engineering Structures, vol. 179, pp. 106-119, 2019.

[17] X. Shen, X. Wang, Q. Ye, and A. Ye, "Seismic performance of transverse steel damper seismic system for long span bridges," Engineering Structures, vol. 141, pp. 14-28, 2017.

[18] X. Shen, A. Camara, and A. Ye, "Effects of seismic devices on transverse responses of piers in the Sutong Bridge," Earthquake Engineering and Engineering Vibration, vol. 14, no. 4, pp. 611-623, 2015.

[19] D. Chiarotto, F. Tomaselli, P. Baldo, M. G. Castellano, and S. Infanti, "Seismic protection of Tuy Medio railway viaducts: design and shaking table tests of the seismic devices," in Proceedings of the 13th World Conference on Earthquake Engineering, pp. 1-14, Vancouver, BC, Canada, August 2004.

[20] J. Wang, Z. Wang, and X. Zhang, A Sliding Mild Steel Cylinder in Bridges, CN200810204146, State Intellectual Property Office of the People's Republic of China, Beijing, China, 2010, in Chinese.

[21] R. G. Tyler, "Tapered steel energy dissipators for earthquake resistant structures," Bulletin of the New Zealand Society for Earthquake Engineering, vol. 11, no. 4, pp. 282-294, 1978.

[22] J. Zhuang, Bridge Shock Absorption, Isolation Bearings and Devices, China Railway Press, Beijing, China, 2012.

[23] H. Wang, R. Zhou, Z. Zong, C. Wang, and A. Li, "Study on seismic response control of a single-tower self-anchored suspension bridge with elastic-plastic steel damper," Science China Technological Sciences, vol. 55, no. 6, pp. 1496-1502, 2012.

[24] China Ministry of Communications, "JT/T 843-2012 Elastic-plastic steel damping bearings for highway bridges," China Communications Press, Beijing, China, 2012.

[25] China Ministry of Communications, "JTG/T B02-01-2008 Guidelines for seismic design of highway bridge," China Communications Press, Beijing, China, 2008.

[26] W. Z. Zheng, H. Wang, J. Li, and H. J. Shen, "Parametric study of SMA-based friction pendulum system for response control of bridges under near-fault ground motions," Journal of Earthquake Engineering, pp. 1-19, 2019.

[27] D. Cardone and G. Gesualdi, "Influence of residual displacements on the design displacement of spherical frictionbased isolation systems," Soil Dynamics and Earthquake Engineering, vol. 100, pp. 492-503, 2017. 


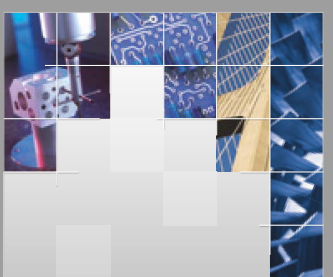

\section{Enfincering}
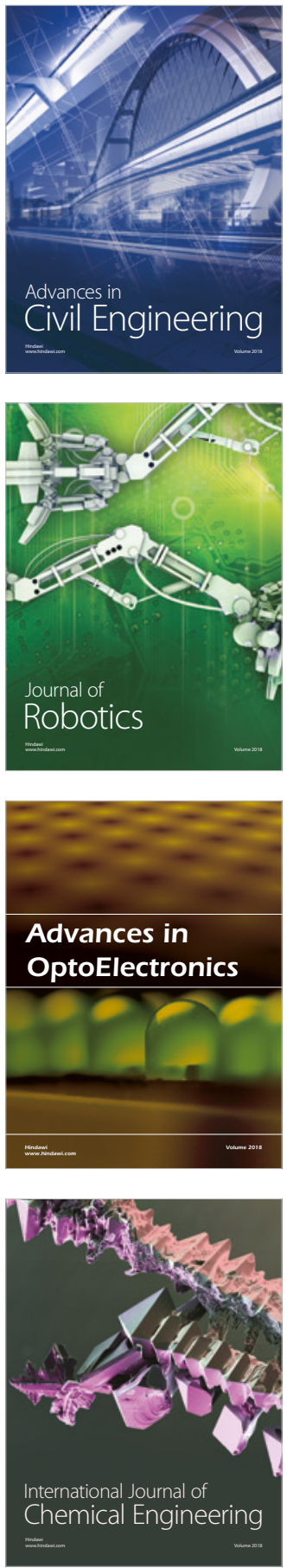

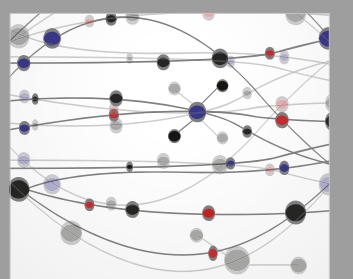

\section{Rotating \\ Machinery}

The Scientific World Journal

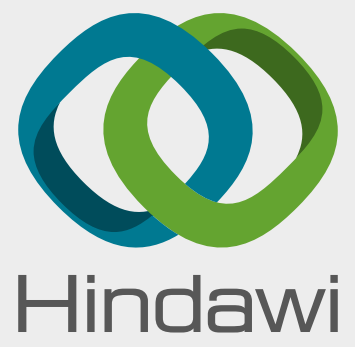

Submit your manuscripts at

www.hindawi.com
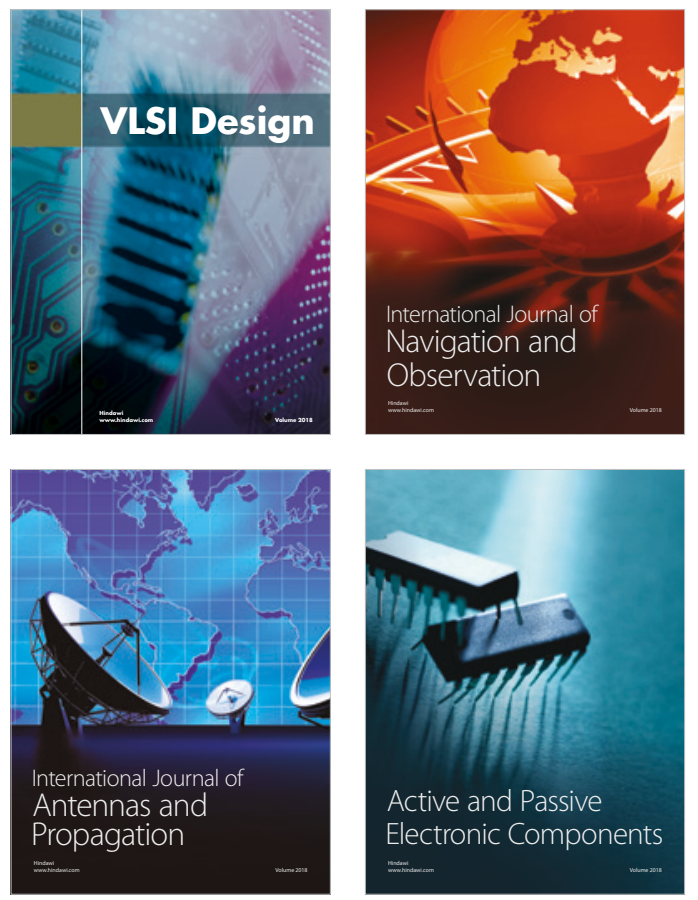
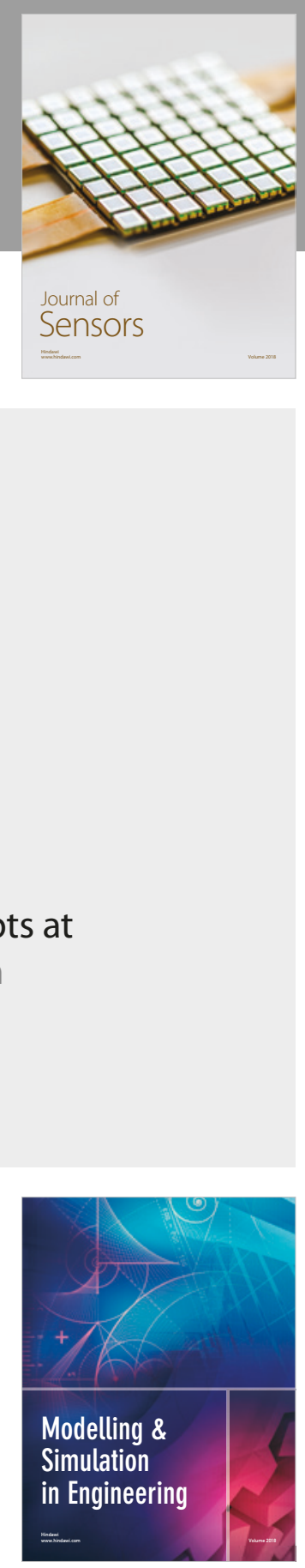

\section{Advances \\ Multimedia}
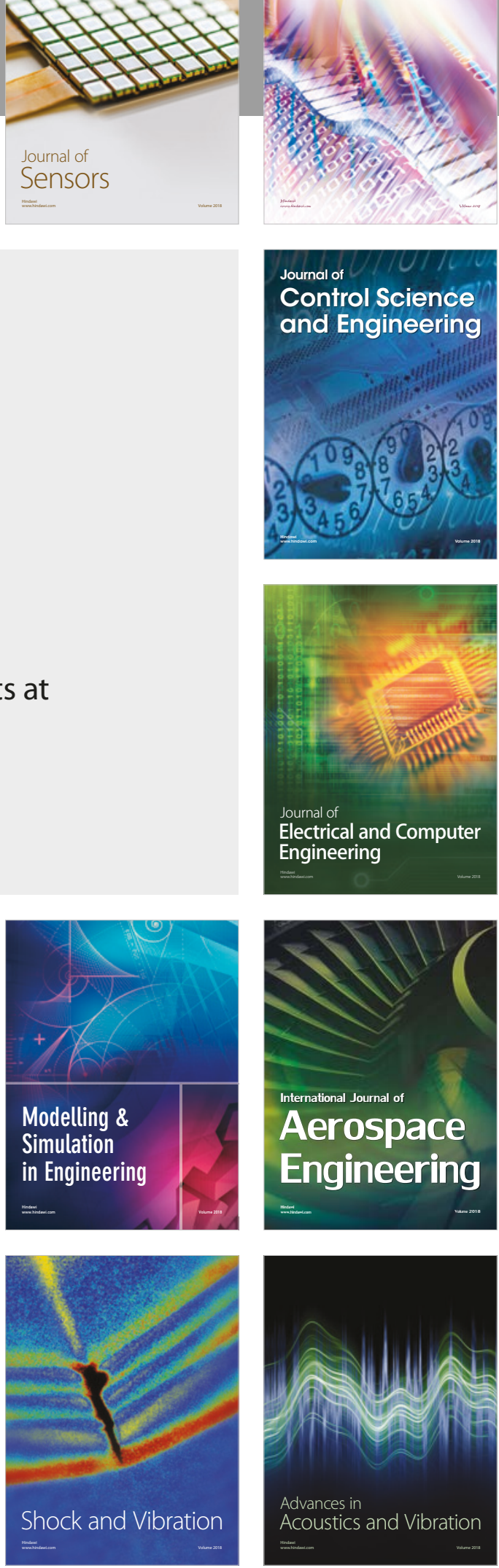